\title{
EUR-ASSESS PROJECT SUBGROUP REPORT ON COVERAGE
}

\author{
Dr. Richard Cranovsky, Co-Chair
}

Swiss Medical Association, Aarau, Switzerland

Professor Yves Matillon, M.D., Co-Chair

National Agency for the Development of Medical Evaluation (ANDEM), Paris, France

\section{Professor David Banta, Secretary \\ Netherlands Organization for Applied Scientific Research (TNO), Leiden, The Netherlands}

Participants: Dr. Michael Bos, Health Council, Rijswijk, The Netherlands; Dr. Per Carlsson, Center for Medical Technology Assessment, Linköping, Sweden; Mr. Loic Geffroy, National Social Security System for Salaried Workers, Paris, France; Dr. James Goldberg, National Agency for the Development of Medical Evaluation (ANDEM), Paris, France; Professor Katrien Kesteloot, Catholic University, Leuven, Belgium; Dr. Pedro Koch, Swiss Federal Office of Social Insurance, Bern, Switzerland; Dr. Simon van der Kooij, Health Insurance Council (retired), Amstelveen, The Netherlands; Professor Lycurgus Liaropoulos, University of Athens, Athens, Greece; Dr. Laura Sampietro-Colom, Catalan Agency for Health Technology Assessment (CAHTA), Barcelona, Spain; and Dr. Julian Schilling, Institute for Social and Preventive Medicine, University of Zurich, Zurich, Switzerland. Contributors: Dr. José Conde-Olasagasti, National Agency for the Evaluation of Health Technology (AETS), Madrid, Spain; Professor Chris Ham, Health Services Management Centre, University of Birmingham, Birmingham, England; Dr. Elias Mossialos, London School of Economics, London, England; and Dr. Thomas Seeger, Auggen, Germany.

\section{CONTENTS}

Executive Summary

1. Introduction

Information on Coverage and HTA

The Future of Coverage and HTA

Structure of This Report

2. General Information on HTA and Health Insurance Coverage Policy

Synthesis of the Literature

Survey of Selected Organizations

Conclusions

3. Description of Health Care Systems, Coverage and HTA

Health Care Systems in General

Regulation of Coverage

Health Care Systems of Eight Countries 
Synthesis: Input of HTA for Coverage Decisions

Other Input of HTA in Health Care Policy: Third-Party Payers

Conclusions

4. The Impact of Technology Assessment on Coverage Decisions:

Cochlear Implants as an Example

Technology of Cochlear Implants

Coverage of CI in Different European Countries

Major European HTA Studies/Assessments on CI

Open Questions

Conclusions

5. Health Technology Assessment and Coverage Policy in Five

European Countries: PTCA as an Example

Dynamics of the Technology

Regulation of PTCA

Effect of PTCA HTA Studies on Coverage Policy Decisions

Discussion

Conclusions

6. Pharmaceutical Coverage

The Pharmaceutical Marketplace and Its Regulation

Consolidating the European Internal Market

Market Authorization and Development of the European

Medicines Evaluation Agency

Definition of Innovation

The International Conference on Harmonization

Coverage and Positive and Negative Lists

Pricing and Reimbursement Policies Toward Pharmaceuticals

The Actions of Member States

Conclusions

7. Models for Coverage Policy

\section{EXECUTIVE SUMMARY}

The issue of health benefits coverage - and its relation to health technology assessment (HTA) - has gained increasing attention in recent years. Economic constraints on health care, as well as the rapid pace of technological change, have forced European countries to face difficult choices in providing such care. The active use of coverage decision making has been proposed as a tool to help rationalize health care, and HTA has been advocated as a necessary activity to improve coverage decisions.

Coverage of health care interventions - called "benefits" from the perspective of the members of a health care plan-means that the costs of these health care interventions are fully or partly financed by a health care plan. Such a plan may be a national health care system or any social or private health insurance system.

Coverage is an important issue in health care policy. Health care policy today aims at improving health care quality within a comprehensive and accessible health care system while controlling costs. This goal can only be reached if safe and costeffective interventions are stimulated and the use of inefficient and unsafe interventions is discouraged. One of the means to channel technology in health care is only to cover cost-effective interventions and to exclude others.

Preferably, decisions to include an intervention in the benefit package should be based on sound information about needs, effectiveness, safety, and costs. In the 
United States, it was found that the largest barrier to decision making for all insurers is "the paucity of reliable information on the effectiveness, safety, and costeffectiveness of new technologies at the time coverage decisions have to be made" (43). The same is undoubtedly true in Europe. Health technology assessment can generate such necessary information.

The idea of linking HTA and coverage is spreading. For example, a national commission in the Netherlands (the Dunning Commission) was asked by the government for advice on making difficult choices in health care (23). The commission acknowledged serious problems of ineffective and cost-ineffective technologies and overuse of effective technologies in the Dutch health care system. It proposed, as part of health care reforms, that a basic benefit package for the population be defined using formal studies of effectiveness and cost-effectiveness. Similar developments are under way in a number of countries. The situation is changing rapidly in such countries as the Netherlands, France, and Spain (particularly Catalonia). Other European countries are considering more explicit coverage policies and their links to HTA.

The goal of this report is to compare the content and process of decision making on coverage in a number of European countries. The hypothesis was that HTA does exert some degree of influence on coverage, but that there are significant differences among the countries of the European Union. The subgroup also aimed to suggest changes for the future to bring coverage and HTA closer together.

\section{Method of the Subgroup}

This report is different from the others in the EUR-ASSESS project. Priority setting, methodology, and implementation all take HTA as their starting point. This report takes a different starting point. It tries to define the decisions in health care policy where HTA can offer valuable input for decision-making processes. The question is not "What has HTA to offer?" but rather "How can coverage decision making be improved by the input of HTA?"

The methods of the subgroup that prepared this report included literature review, a survey of a number of those involved in coverage, development of country case studies, exploration of HTA impact on coverage with two technologies (cochlear implants and invasive cardiology therapy), discussion in the subgroup, and synthesis. Because coverage policy is generally more developed in the area of pharmaceuticals, a special contract was let to gather specific information in this field. The literature was of limited value in making this report, so the knowledge and experience of this subgroup's participants probably had a larger role than in other subgroups.

Based on the collected information, the subgroup had extensive discussions on optimal models of decision making concerning coverage policy. It was a working hypothesis that the role of HTA should be strengthened in coverage.

\section{Background}

From the beginning, organized health care systems and payment plans have had to ciefine a package of benefits. Traditionally, these have been defined by what doctors do. In other words, doctors have determined what they thought to be effective, and the system has provided payment for application of those technologies.

Evidence of many problems in health care, including the widespread application of ineffective technologies and the widespread inappropriate application of effective technologies, has brought this traditional system into question. An example of this can be found in the Netherlands, where the Health Insurance Board published a list of 126 health technologies that lack evidence of effectiveness. 
The growth in the field of HTA has led to an alternative: to determine benefits coverage through a process of HTA. As will be seen, this alternative is not yet a predominant method of decision making. Indeed, it is still a marginal activity, although a growing one. As one participant in the subgroup noted, "We must take as a basic assumption that those things that doctors do now are effective. Otherwise, we have to assess everything in health care in a short period of time, which is impossible." In short, all systems continue to function with an undefined and unevaluated benefit package. HTA activities related to decisions on the benefit package so far deal mainly with a few specific types of technologies, especially new, expensive technologies and pharmaceuticals.

Studying coverage is difficult. The first reason it is difficult is that coverage regulation is a policy measure on the macro-level. It is not effective in restricting decisions to use ineffective, unsafe, or unnecessary interventions at the bedside (at the micro-level). Indeed, the vast majority of decisions at the bedside is essentially unaffected by coverage policy itself. Mental health care, home health care, chronic disease care, and nursing home care are examples of huge areas of activity that are essentially not affected by coverage policy. There may be implicit restrictions from contracts at the meso-level between regional or local associations of providers and health care plans or payers of any kind, but it is very difficult to discover the input of HTA in these decisions.

The second reason that studying coverage is difficult is that coverage decisions in a certain country depend on the health care system of that country. Time and resources did not allow studying all countries. Therefore, only a few European countries were taken by the subgroup as examples to illustrate the differences in the use of HTA in coverage policy decisions in relation to the health care system of that country.

\section{The Importance of Indications}

Cost-effectiveness and necessity of a technology are related to the indications for its use, in terms of symptoms or suspected diagnosis and other factors such as age. Indications reflect both the prevailing theory concerning the health problem and the empirically established approaches to it. Both indications and outcomes show significant differences among countries and/or regions.

Bone marrow transplantation is effective for some hematologic diseases, but may be questioned in others, such as metastatic breast cancer. Magnetic resonance imaging (MRI) is useful for the diagnosis of certain neurologic diseases, but not for the diagnosis of most cases of headache. Periodic mammographic screening can reduce breast cancer mortality, but there are questions if it does so for women under 50 years of age.

It is impossible to list all covered interventions on such a specified level that all possible indications for a technology are included. Therefore, description or restriction of coverage is not a sufficient instrument to restrict undesirable interventions. Other measures must be added to influence the providers of health care, such as incentives, professional protocols, feedback, budgets, contractual agreements, education of physicians, and provision of reliable information to consumers of care. These measures help assure that justice is done to the professional responsibility of physicians and to the specific circumstances of each patient.

\section{The Diversity of European Health Care Systems}

Health care systems of European countries diverge significantly and in many ways. The diversity has its roots in each country's history and in political and cultural 
differences. This diversity has influenced the content and, even more, the process of coverage decisions and other regulatory measures that are intended to improve quality of care and reduce costs.

Coverage decisions are often made by the central government, but in decentralized or market-oriented systems there are other decision makers. Private insurers may enlarge the package of benefits in order to attract more clients; this may lead to inclusion of interventions lacking evidence of effectiveness. Governments may intervene in such cases by restricting the number of providers, by regulating the private sector, or even by forbidding certain health care interventions. This dynamic mix of government and private decision making makes coverage particularly complex.

There are three principal methods by which provision of health care benefits can be arranged:

1. Patients are reimbursed for their medical bills (the reimbursement model); in this model there is no relationship between provider and payer.

2. The state owns the hospitals and the individual providers are salaried (the integrated model).

3. There are contracts between providers and third-party payers (the contract model).

Most countries have a combination of two or even three of these systems. Often there are different systems for primary care, secondary care, pharmaceuticals, longterm care, and other types of care. In some countries voluntary and obligatory health insurance are complementary; sometimes the higher income classes are privately insured.

In terms of the relations between payment and HTA, it is interesting that the health care systems of most European countries seem to converge to a publicly financed system with payments by third-party payers under defined contractual relations, with competing providers of health care and a more or less moderate degree of competition between payers. These systems allow both cost-containment measures and decentralization, giving providers a high degree of clinical autonomy. In these systems there remains a certain amount of government regulation of prices, budgets for third-party payers, and/or hospitals, restricted volumes of providers, and sometimes big-ticket technologies.

An important conclusion is that there seems to be a moderate but general shift in regulatory power from providers and from governments to the third-party payers.

\section{Coverage in Different European Health Care Systems}

Coverage decisions are different in different countries and depend on the nature of the health care system. They can be made on a central or regional level. They can be made by government, by third-party payers, or not explicitly at all. They can be different in varying fields of health care, such as pharmaceuticals, medical devices, and medical procedures. They can emphasize different sources of information, such as data from prospective studies, formal meta-analyses, or opinion of clinical experts.

In the strict sense, coverage means that health care technologies are paid for by a health plan. Technologies are admitted or removed from the "list of benefits." But there are other possibilities to withhold or restrict the use of health technologies. A government can refuse to admit technologies to the "market" of the country, often for safety reasons, as in the case of thalidomide, a drug with severe teratogenic effects. Since the thalidomide case in the 1960s, all European countries have established approval procedures for admittance to the market. Pharmaceuticals are not admitted when they are unsafe, ineffective, or (more recently) when they are less 


\section{EUR-ASSESS Project Subgroup on Coverage}

cost-effective than drugs with the same therapeutic objective. However, the assessment done in these cases is quite limited and has not considered such factors as relative advantages over other drugs, comparison to alternative treatments (such as lifestyle changes or surgery), and societal implications (see report of the Subgroup on Methods).

There is an increasing trend to regulate medical devices in a similar manner. However, assessment here tends to be quite technical, and clinical efficacy and safety are generally not part of the process.

Medical procedures, especially complicated technologies such as transplants or treatments for end-stage renal disease, can also be forbidden or restricted by governmental regulation (licensing and "planning"), for reasons of efficiency, distribution, and/or quality of care. Such decisions are part of the social policy of a country and are not necessarily responsive to HTA results.

There are also methods to influence the use of technologies by health care providers through contracts concerning volume, payment regulations, budgets, increasing responsibility for cost-effectiveness, and disseminating information on costef fectiveness to providers to try to change their knowledge and practice. Such methods are of particular interest to affect decisions by physicians (micro-level). One important goal is to diminish the use of technologies that have not been proven to be effective for the intended application. Another goal is to increase the use of scientifically proven and needed technologies.

Strictly speaking, admittance to the market and promotion of cost-effectiveness cannot be called coverage policy, but they aim at the same goals. They also need HTA as an indispensable input.

Among countries included in this study, Switzerland has perhaps gone farthest to develop an explicit and transparent process for coverage policy. Extensive positive lists for pharmaceuticals, medical devices, and procedures have been developed. New technologies are systematically reviewed. In case of questions, HTA can be required, or data banks for continuing surveillance of the technology can be established to collect data after the technology comes into widespread use. Under a 1995 law, all technologies in the Swiss health care system could be subject to assessment.

The Netherlands is another country that has made HTA a centerpiece of its coverage decisions. In the area of pharmaceuticals, national premarketing approval requires evidence of safety and efficacy, but the Health Insurance Board also presents extensive information on cost-effectiveness to all physicians. A license is required for a number of technologies that are restricted and regionalized, and these decisions are based on HTA. A small but growing number of procedures is not covered or only covered on restricted indications by the national health insurance funds; these decisions are based on HTA. The Netherlands has a special fund, administered by the Health Insurance Board, for studying the cost-effectiveness of devices and procedures.

Spain has a national law requiring HTA in the coverage of new procedures. In Catalonia, coverage is frequently based on synthetic reports by the HTA agency. For some technologies, coverage is allowed for restricted indications until adequate data on efficacy and efficiency are available. In case of lack of data, a fund is available to carry out original research.

In the United Kingdom, there are no formal coverage decisions by the National Health Service, but the District Health Authorities are regularly informed on the cost-effectiveness of medical procedures, which may influence their priorities in purchasing health care. 
While these experiences are still developing and have had only a moderate impact so far (outside the field of pharmaceuticals), they are growing and indicate the trend for the future. The other countries examined by the subgroup show similar trends, although generally not so well developed.

Reasons identified for lack of use of HTA information among the countries studied included the political nature of the decisions and lack of information on effectiveness, costs, and appropriateness.

Developments in the United Kingdom are particularly interesting since the strict split between providers and purveyors has proceeded further than in other countries. Contracts are meant to specify volume, quality, and costs of health care that are "bought" by District Health Authorities or fund-holding general practitioners. The thrust to develop information on cost-effectiveness gives good opportunities in this system to improve the efficiency of health care. This indicates that one of the consequences of the introduction of market principles in health care is not only a power shift from the central government and providers to third-party payers, but also an increasing sharing of responsibility of these parties who become partners in trying to improve health care and efficiency. Such developments offer many opportunities to HTA.

\section{The Cochlear Implant Case}

Cochlear implants (CI) were chosen as an interesting and well-documented case study to illustrate the relevance of HTA for coverage decisions with regard to a well-defined procedure. Cochlear implants were chosen with full knowledge that they concern only a small percentage of people and so have a comparably insignificant economic impact.

The technology of cochlear implants was developed during the last 30 years and was first introduced to Europe in 1984. Today, cochlear implants are widely accepted as an appropriate treatment for deafness. More than 10,000 implantations have been performed worldwide; in Europe there are currently more than 130 active cochlear implant clinics located in nearly all countries. CI is a technology that is rapidly progressing technologically.

However, there is still considerable controversy with regard to the indications for the procedure, whether to exclude prelingually (i.e., before the acquisition of language) deaf children on the one hand and/or whether to include older persons with some degree of hearing loss on the other hand. Moreover, parts of the deaf community (those who use sign language and are concerned about the impact on their subculture) fight against cochlear implants and its coverage (see report of Subgroup on Methods). Because of these questions, decision makers have been unsure of how to proceed and have asked for HTA studies as a basis for coverage decisions. CIs have been evaluated in a number of clinical and cost-effectiveness studies in Europe. Several HTA programs have evaluated CIs. Coverage decisions have been closely linked to the outcomes of these studies.

Throughout Europe, reimbursement for CIs varies from full coverage for all who qualify for a CI to countries without any provisions for reimbursement of this treatment. Full coverage of $\mathrm{CI}$ is available in six countries and is provided either by public health insurance schemes, as in Scandinavia, or by sickness funds that operate in Belgium, Germany, and the Netherlands. In most other countries, the number of patients is limited, mostly by limited public or hospital budgets or by restrictions on patient selection criteria.

The case study shows that HTAs have had a general influence on health policy relating to CIs in France, Catalonia, Spain, Germany, and Switzerland. HTAs have 
had a direct influence on coverage and reimbursement decisions in the UK, Switzerland, France, the Netherlands, Germany, and Catalonia.

Because of continued controversy on indications for CIs and subsequent rehabilitation and social integration, especially with regard to deaf-born infants, several countries are undertaking long-term assessment studies concerning cost-benefit and quality of life. The results obtained are expected to be a basis for a revision of indications expressed in coverage decisions.

Cochlear implants are a case in which HTA has had a clear effect on coverage decisions. However, there are great national differences in the requirements as to scope and strength of evidence in the requested evaluative studies. The requests for HTA have depended strongly on the structure and financing of the health care system of the specific country. In addition, studies have been conducted independently and often in parallel in many European countries. $\mathrm{CI}$ is also a case illustrating that coordination of assessment efforts among European countries could be very rewarding.

\section{The Case of Percutaneous Transluminal Coronary Angioplasty}

Invasive cardiologic therapy was chosen as a case study in the project as a more complex technology affecting many people. Invasive cardiology therapy is a very dynamic field that includes such technologies as cardiac surgery, percutaneous transluminal coronary angioplasty (PTCA or balloon angioplasty), and other newer methods, including lasers and stents. Because PTCA is widely diffused yet still in a state of dynamic development, it was chosen as the test case for description in this report.

The case was developed by country case studies of Catalonia, Greece, the Netherlands, Sweden, and Switzerland, each carried out by a member of the subgroup, supplemented by published information and data on the extent of diffusion in different countries.

PTCA was introduced to Europe during the period 1980-83. At the time of PTCA's introduction, it was considered a partial substitute for coronary artery bypass grafts (CABG), especially in cases of single-vessel disease. This substitution took place most rapidly in university cardiac centers (by 1990 in Switzerland and the Netherlands), while nonuniversity cardiac centers continued to use CABG, even for single-vessel disease. In the early 1990s, indications for PTCA expanded greatly. As a result of different factors, the number of PTCA procedures has increased 5 to 10 times during the last 8 or 9 years. At the same time, the number of $C A B G$ procedures has doubled in most countries.

Central and regional governments have tried to implement planning measures directed at invasive cardiology, including PTCA, both through legislation and recommendations, with some success. Limitations in success may be related to improvements in the technology, new indications for PTCA, more revascularization procedures due to restenosis after PTCA, and size of the payment per procedure.

HTA has been carried out on PTCA in several countries, especially in Catalonia, the Netherlands, and Sweden. Most studies have been requested by third-party payers or organizations indirectly related to the establishment of coverage policy. The diversity of policy questions addressed can explain the range of study methods found in the HTA documents. Planning-related issues have been the most extensively studied issues.

HTA studies have had some effect on the planning of PTCA services. In Catalonia, PTCA and CABG studies have been the basis for creating a geographical 
preferential reference pattern for these technologies and specific contracts with providers of the technology. The Netherlands developed planning decrees on cardiac catheterization and cardiac surgery on the basis of an HTA study.

HTA studies have also affected coverage of PTCA. In the Netherlands, the use of laser revascularization has been discontinued since a coverage decision not to pay for it on the basis of a cost-effectiveness analysis comparing PTCA and laser vascularization including PTCA. In Catalonia, changes in the payment system to increase activity in this field were developed based on HTA results.

A structure for HTA (an organized agency or council) has been an important prerequisite for such studies to have an impact on coverage policy decisions in PTCA. Coverage decisions in Greece, for example, have been made without reference to a formal HTA. It is not known how coverage decisions are made in such a case. The case study points out that an organized HTA program may be necessary if coverage is to be used to improve the quality and efficiency of health care.

\section{A Model for Coverage Policy}

Coverage decisions largely remain implicit, not transparent, and political. Improving the quality and cost-effectiveness of care seems to require a large input of HTA. In addition, it requires a coverage policy that is more explicit, rational, and transparent. Integrating HTA into coverage decision making requires that those making coverage decisions and those doing HTA work closer together. They must consult regularly, understand each others' problems, and work together to improve care.

An idealized model for coverage policy involving HTA might involve these steps (see report of the Subgroup on Methods for a more extensive discussion of methods):

1. Identification of the technology in question. The identification might be done by either the coverage body or the HTA program. The coverage body must determine if the technology is a potential priority for an assessment. If so, it would ask the HTA body for an assessment.

2. Literature review to determine availability of information. If sufficient information for an HTA is available, the HTA body would propose an assessment to the coverage body, including a time frame for the assessment. If not, the HTA body would propose supporting an appropriate high-quality study, such as a randomized clinical trial (RCT), and perhaps a simultaneous cost-effectiveness analysis. If this proposal is accepted, a delay of several years in the decision can be expected. Naturally, the coverage body may reject the option for an assessment and make the decision on other grounds.

3. Synthesis of available information, including clinical, economic, ethical, and social data, leads to an HTA. Extensive expert input is sought in this synthetic process. The synthesis leads to judgments and perhaps recommendations from the HTA body to the coverage body.

4. A coverage proposal is developed by the coverage body. After expert review, including review by the HTA body, the coverage decision is made, published, and promulgated.

As already noted, several countries have worked to develop such a process. Switzerland has developed an extensive manual describing the coverage process used in that country. This manual is available in German, French, and English. The manual goes far to meet the goal of spelling out a rational, explicit, transparent process.

\section{Conclusions}

Benefits coverage is a potential tool for improving the quality and efficiency of health care. However, it is only one of the possibilities for meeting these goals. Other possibilities include planning/regulation (admission to the market, control of volume 
and location), contracts of third-party payers, and payment decisions (general or specific budgets, price setting, reference systems, co-payment by the users). Mechanisms for regulation (reimbursement and authorization) differ greatly from one country to the other and are difficult to compare because of differing approaches and mechanisms. In the majority of European countries, reimbursement programs are administered separately from regulatory programs, which seek to assure safety and to protect the public health.

Benefits coverage has, until fairly recently, been done almost entirely implicitly. Benefits have been extended to the "usual," "customary," or "standard" practice of physicians, hospitals, and other health care providers. Exclusions have been based on such terms as "experimental," "investigational," "not proven," "cosmetic," or "too expensive."

Efforts have begun to make benefits coverage more explicit. So far, most of these efforts have been at the margin, concerning only new, visible technologies. Overall, the connection between benefits coverage and HTA is quite limited at this time.

There have also been proposals to stop using terms such as "investigational," which cannot be precisely defined, and to use instead "effective" based on scientific information, with clinical input, and "cost-effective." Societal acceptability can be another criterion. Such proposals have been implemented partially in a few countries, such as Switzerland, Catalonia, and the Netherlands.

The legal basis of changes in coverage policies needs to be examined in any country that contemplates such process alterations. For example, the law may state that "customary medical practice" is to be covered. Laws may need to be changed to make decision making on grounds of effectiveness explicit.

Proposals have been made to define a basic benefit package and to base it on effectiveness, cost-effectiveness, and societal acceptability. Efforts in this direction have begun in Switzerland, Spain, and the Netherlands. This is a long-term task, not to be accomplished within a decade. So far, as indicated, efforts have focused on the examination of new technologies for inclusion in a benefits package. Some countries, such as the Netherlands, are also examining accepted older technologies and beginning to exclude them from coverage by a "negative list."

\section{Limitations of HTA Impact on Decision Making}

Effectiveness (and efficacy) can be reliably determined by clinical trials and synthesis of existing scientific information in many cases. Still, good scientific information and data are lacking for many existing technologies. Cost-effectiveness is more difficult to determine, since analyses always depend on assumptions, which are open to manipulation. Societal acceptability raises other obvious problems and has not been studied very thoroughly. Therefore, human judgment, including expert opinion, will always play an important role in coverage decisions. Furthermore, HTA and coverage decisions may be subject to political pressures, including commercial efforts to influence decisions and professional lobbies. It is important that HTA be institutionalized in such as way as to assure the excellence of its results. Decision makers must be prepared to reject recommendations that are not based on the best quality of information (see report of Subgroup on Methods).

\section{HTA, Coverage Bodies, and Insurance}

Health care technology assessment agencies need to work interactively with those making coverage decisions to learn what information would be most useful. It is 
clear that any coverage recommendations need to be clear and definitive, including a clear-cut statement of recommended indications for use.

Doubtful or negative HTA results should also be explicitly communicated to the coverage body and to the medical community. The conclusion may be that more and/or better data are necessary to make valuable recommendations. The HTA may also lead to a simple, well-documented but negative conclusion concerning the inclusion of the technology in the benefit package of an insurance plan.

Depending on HTA results and coverage decisions, payers, including insurance companies, can do much more to influence health care practice. A possibility that is gaining increasing attention is to use contracts to assure efficiency and quality of health care. For example, when there is a threat that a contract will be moved to an alternative provider, the incentive to improve services is probably greater.

\section{Perspectives}

The foundation for an effective activity in HTA has been developed in Europe. A number of successful assessments have been carried out, HTA is respected throughout Europe, and the impact of assessments is growing. During the work of the Subgroup on Coverage, several examples of the influence of HTA results on insurance coverage policy have been identified.

The two key needs at the moment, from the perspective of the subgroup, are for more national and regional resources in assessment and for an international network of institutions, programs, and people. In time, organizations such as HTA agencies and the Cochrane Collaboration will produce an increasing amount of information of value to policy and practice.

The point is that those responsible for health policy and insurance benefits need to demand better information for their decision making. To meet this goal requires educating and orienting those decision makers to the potentials of HTA in coverage decisions. It would be beneficial as well if coverage bodies developed and used systematic, standard, transparent approaches to making coverage decisions. A publicly available manual describing the process of making coverage decisions, as has been developed in Switzerland, is potentially beneficial in this regard.

\section{Recommendations}

1. Health technology assessment agencies must be prepared to give appropriate and comprehensive information to coverage bodies in a timely fashion. HTA programs need to improve their relationships with coverage decision makers.

2. Research into health care policy is important for HTA agencies. Studies of direct policies such as coverage policy are important, as are related policies such as those of the courts. HTA agencies need to learn much more about how health care deals with decision making. Case studies of successes and failures of HTA may be particularly valuable.

\section{CHAPTER 1: INTRODUCTION}

Health technology assessment (HTA) has been progressively developed during the last two decades throughout the world, but especially in Europe. During the last decade, under the pressure of economic constraints, major changes have been initiated in the health care systems of most industrialized countries. The combination of limited resources for health care and technological progress has forced those responsible for health care policy making to set priorities and make "enlightened" choices. 
One important aspect of choice is that new health care technologies should become accessible to the entire population and obsolete technologies abandoned. Effectiveness, costs, and ethical and legal issues in health care have become important to everyone: health care providers, policy makers, and the public. HTA has come to be seen as an indispensable tool to assist all partners in health care in making the often painful choices that are necessary (29).

In this context, health insurance coverage has come to be seen as a policy that could benefit greatly from HTA. One major issue has been to define a package of basic benefits that would be available to the entire population. The Netherlands gives perhaps the clearest indication of this philosophy (12). A special government commission, chaired by a prominent professor of cardiology, stated that limits to care are necessary and that coverage is an important tool for defining limits to care and for making a basic package of benefits explicit. The Dunning Commission stated that technologies covered by health insurance could be subject to four "screens" or "sieves" (23). First, is the care necessary, meaning (for example) is it necessary to assure normal function or to protect life? Second, is the intervention proven to be ef fective by controlled clinical trials? Third, is the care efficient, meaning is it shown to be cost-effective by a formal analysis? Is the cost reasonable when compared to the benefits? Fourth, is it possible to leave the care to individual responsibility? For example, the commission concluded that in vitro fertilization and homeopathic medicines could be left to individual responsibility. The commission concluded that applying these four screens in selecting technologies to be included would result in a rather extensive benefit package without excessive costs.

Because of this growing attention to coverage as a tool for making health care more effective and cost-effective, the EUR-ASSESS Project supported a Subgroup on Coverage to examine issues in this area.

From the beginning of the project, the partners in the project had the impression that health benefits coverage was not equal or comparable in European countries and that decisions were rarely based on HTA results. An analysis of decision processes was expected to give a better picture of the current situation and perhaps stimulate a more intensive application of HTA methods in coverage decisions. Actions following an analysis of the existing situation should result in decisions more in accord with the wish to spend limited health care resources more effectively, improving quality of care and the health of the population.

\section{Information on Coverage and HTA}

A review of accessible literature (reviewed briefly below) resulted in little usable information. Therefore, the subgroup carried out an exploratory survey concerning the coverage decision process in several countries (also reviewed briefly below). Information gathered from these sources, plus discussions in the subgroup, made it clear that the question of coverage and HTA in Europe can only be studied in the context of national, continually changing, health care systems. In short, the context for coverage is extremely important. Therefore, a brief description of health care systems in selected countries, focusing on health benefits coverage and HTA, was made by the subgroup's participants. It was also decided to analyze two technologies, cochlear implants and invasive cardiology therapy, to gain insights in coverage decisions in various countries. In addition, information on coverage and pharmaceuticals was analyzed.

The organization of the health care systems in European countries varies greatly from country to country, so it should come as no surprise to find that coverage 
decisions also vary greatly. There are relatively few commonalities in coverage decisions from country to country, considering the diversity and complexity of this process. As will be shown below, coverage of medical devices and procedures is often not the result of any explicit processes. When it is, the processes are often not transparent and are undocumented. In many cases, no explicit decisions are taken, but a new technology just diffuses into care with no analysis of its possible benefits. Overall, even after the subgroup's work, relatively little is known about how countries decide which technologies to cover in health care. This issue deserves much more concentrated study.

The issue with pharmaceuticals is also complex, but they are better regulated. However, generally speaking, the decisions on pharmaceuticals are made by regulatory agencies that consider only a limited aspect of the possible consequences of adoption and use of a particular drug.

HTA results are integrated in coverage decisions to a very different degree in individual countries. First, HTA is not developed equally in all European countries. Second, policy makers are often not aware of the possible advantages of implementing HTA results. Finally, the role of the main partners in the health care system is changing in a number of countries, with a tendency to base decisions more on "health market" considerations than on scientific arguments that could be the result of HTA studies.

Again, the situation with pharmaceuticals is quite different. A degree of common information on the safety and efficacy of pharmaceuticals is available through regulation, and coverage is more uniform and based to an extent on HTA information. However, since the information used by regulatory agencies is generally limited, in a sense regulation impedes the development and use of HTA information in policy decisions, including coverage.

\section{The Future of Coverage and HTA}

For the good of patients, health care providers, and those responsible for paying for care, the involvement of HTA in policy making, including that concerning health care benefits coverage, needs to be strengthened. The Subgroup on Coverage feels that it has confirmed the initial hypothesis that it is important to strengthen the relationship between coverage and HTA.

This report identifies some critical issues and hopefully will contribute to the idea of better utilization of HTA results in coverage decisions. While these are preliminary, some elements of models for improvement of the relationship between HTA and coverage policy are also identified below.

\section{Structure of This Report}

Chapter 2 reviews publication concerning HTA and coverage and presents the results of the survey. Chapter 3 summarizes information on the countries selected. Chapters 4 and 5 present the cochlear implant and invasive cardiology therapy cases. Chapter 6 discusses the situation with coverage of pharmaceuticals. Chapter 7 presents some models for integrating coverage and HTA.

While the subgroup is responsible for the entire report, some members had special responsibilities. Richard Cranovsky developed and carried out the survey of those involved in coverage decisions. Yves Matillon and Richard Cranovsky had the main responsibility for the literature review. Simon van der Kooij and Per Carlsson collected and analyzed the material on country health care systems (an extended version is available from Carlsson). Thomas Seeger and Richard Cranovsky developed the 
case of cochlear implants (an extended version is available from Cranovsky). Laura Sampietro and Mike Bos were mainly responsible for the invasive cardiology therapy case (an extended version is available from Sampietro). Elias Mossialos wrote a paper on pharmaceutical coverage that was the basis for material in the chapter on that subject (the full version is available from Mossialos). The overall synthesis, including the information on explicit models, was developed primarily by Richard Cranovsky, Julian Schilling, Siem van der Kooij, Pedro Koch, and David Banta.

\section{CHAPTER 2: GENERAL INFORMATION ON HTA AND HEALTH INSURANCE COVERAGE POLICY}

\section{Synthesis of the Literature}

General references related to coverage policy are abundant in the United States as well as in other industrialized countries. ANDEM (the French HTA agency) has maintained a bibliographic database since 1993 that has identified about 150 publications on this subject worldwide. These publications are of different sorts, mainly in English, and contain some information relating to HTA, regulatory issues, or the financing of health technologies. However, on examination, few of these references give any realistic information on HTA and coverage issues.

At the same time, the papers treating the relationship between HTA and coverage or insurance benefits policy in Europe are very few $(20 ; 23 ; 58 ; 69)$. Those identified that are useful include papers on the Netherlands $(9 ; 12)$, Sweden (34), Germany (35), Switzerland (36), the United Kingdom (54), and France (68). However, while these papers gave valuable information on the health systems of the particular countries, they generally did not give detailed information on the real processes of coverage decision making.

Besides these few references, several documents fall in the category of "gray literature" and generally will not be found in computerized data banks. Among them are policy papers of social sickness funds or private insurers, governmental decrees, and regulatory documents. The Spanish Real Decreto 63/1995 on the Organization of Health Services Provided by the National Health System (40) and the Swiss Manual for Standardization of Clinical and Economic Evaluation of Medical Technology (63) can serve as examples of such documents. The Swiss approach is presented in some detail in Chapter 7. The documents do indicate the growing visibility and importance of the coverage process for European countries.

A fundamental issue in coverage is the language used in exploring the relationship between HTA and coverage policy or that presenting a specific coverage recommendation. The literature uses terms such as "usual and necessary," "experimental," and "cosmetic." These terms actually hide the real issue of coverage. This complex issue was very well analyzed in the article "Benefit Language" by Eddy (24). Eddy proposes the replacement of such essentially unusable or subjective terms by explicit terms that can be defined scientifically, such as "efficacy" or "effectiveness." Most of the definitions concerning, e.g., medical conditions, health interventions, indications, evidence, and outcomes are universal and can be applied to other countries than the United States.

There are several other examples of articles treating the problems in nonEuropean countries that contain information that might be useful for decision makers and payers in Europe $(10 ; 14 ; 15 ; 25 ; 28 ; 30 ; 31 ; 38 ; 46 ; 49 ; 52 ; 53 ; 66)$. However, the usefulness of these articles seems quite limited, partly for historical reasons. It is important to keep in mind that HTA is currently of importance not only for "social insurance 
Table 1. Cost and Effectiveness in Medical Coverage Decisions: Percentage of Respondents Who Would Cover a New Technology Given a Cost and Effectiveness Profile Relative to a Standard Technology

\begin{tabular}{lccc}
\hline & \multicolumn{3}{c}{ Relative effectiveness } \\
\cline { 2 - 4 } Relative cost & Greater effect & Equal effect & Less effect \\
\hline Greater cost & $90 \%$ & $24 \%$ & $3 \%$ \\
Equal cost & $99 \%$ & $95 \%$ & $4 \%$ \\
Less cost & $98 \%$ & $99 \%$ & $14 \%$ \\
\hline
\end{tabular}

Source: Steinberg et al. (55)

plans" or traditional sickness funds but also for the growing sector of private health care organizations and private insurers.

The literature on the change in the meaning of some definitions is not only semantic but also practical. A few years ago it was much easier to agree with definitions of coverage and reimbursement such as those given in Chapter 1. In changing health care systems, with modifications in the way that resources are distributed (e.g., fundholders system in the United Kingdom or different forms of managed care), some classic concepts and definitions have taken on a different meaning (32).

With these cautions in mind, a few papers are worthy of mention, although they do not refer to European health care systems. One good example is the document published by the U.S. Office of Technology Assessment (OTA) in 1995, Coverage of Laser Technologies (43). The report states that the largest barrier to decision making for U.S. insurance is ". .the paucity of reliable information on the effectiveness, safety, and cost-effectiveness of new technologies at the time coverage decisions have to be made." It contains general chapters on coverage decision making by private insurers and by the Health Care Financing Administration (HCFA). The Blue Cross and Blue Shield Association makes coverage recommendations based on a formal process that includes a medical advisory panel. A technology can be eligible for coverage if five criteria are met:

1. The technology must have final approval from a regulatory body;

2. There must be scientific evidence concerning the effect of the technology on health outcomes;

3. The technology must improve health outcome (e.g., survival, quality of life, functional status);

4. The technology must be as beneficial as technologies currently existing; and

5. The improvements must be also attainable outside research settings.

The coverage decision-making process of HCFA is more complex and not as explicit as one might expect. The coverage decisions are made by Technology Advisory Committees, sometimes with advice from the Office of Health Technology Assessment (OHTA) of the federal government. The proposals are published in the Federal Register for comments and subsequent adjustments. But in reality, Medicare contractors review technologies themselves and make their own coverage decisions. National coverage decisions refer to a few selected technologies $(43 ; 53)$.

What is the basis for coverage decisions? Little is known in this area. Steiner, Powe, and Anderson $(56 ; 57)$ carried out a study in the United States that examined some aspects of this question. Table 1 shows the relationship between cost and effectiveness in medical coverage decisions. 
Table 2. Who Should Pay for Clinical Care Associated with Use of "Special-Priority" Technologies: A Proposal

\begin{tabular}{llc}
\hline Type of technology & Entity to pay for the technology itself & $\begin{array}{c}\text { Entity to pay for } \\
\text { care surrounding } \\
\text { use of the } \\
\text { technology }\end{array}$ \\
\hline $\begin{array}{l}\text { Drug } \\
\begin{array}{l}\text { Device or expen- } \\
\text { sive biotech- } \\
\text { nology product }\end{array}\end{array}$ & $\begin{array}{c}\text { Insurers and HMOs (for substituting for cov- } \\
\text { ered products) } \\
\text { Manufacturer or trust fund (for other product } \\
\text { substituting for covered products) } \\
\text { Manufacturers or trust fund (for other } \\
\text { products) } \\
\text { Trust funds }\end{array}$ & $\begin{array}{c}\text { Insurers and } \\
\text { HMOs } \\
\text { Insurers and } \\
\text { HMOs }\end{array}$ \\
$\begin{array}{l}\text { Procedure } \\
\text { Tanufarer }\end{array}$ & $\begin{array}{c}\text { Insurers and } \\
\text { HMOs }\end{array}$ \\
\hline
\end{tabular}

Abbreviation: $\mathrm{HMO}=$ Health maintenance organization.

a If a trust fund is used, the manufacturer would pay a percentage of future profits to the fund. Source: Steinberg et al. (55)

The table shows that cost makes little difference if effectiveness is greater. With equal effectiveness, however, cost becomes more important. Few would cover a technology with less effectiveness, although if it were also less costly it might be of interest.

Among the critical issues in coverage decision making, the problem of innovative technologies was treated in several papers $(20 ; 52 ; 55)$ (Table 2). The exhibit "who should pay for clinical care associated with use of special-priority" technologies is based on the situation in the United States, but is also informative for Europeans.

The proposal is to assure that high priority technologies can enter the benefit package in an era where it is increasingly difficult. Increased cost pressure threatens to curtail development of new technologies. The proposal seeks to assure that experimental technologies can be tested. As the authors say, "Controversy over how to pay for and study experimental technologies goes beyond devices . . . and reflects the absence of a broader policy for ensuring that potentially valuable new technologies can be introduced and tested in a rational, efficient manner. . . ."

The reason for this situation was given by Telling (65): "Cost is becoming a dominant factor in the decision of third-party payers and appears to be replacing patient benefit as the principal factor for determining whether an innovative technology is adopted and used."

Finally it is worthwhile to quote the synthetic view of Fineberg (27) concerning HTA and coverage decisions: "First, universal coverage may be attained in a singlepayer system or in multipayer system. Second, universal coverage alone does not ensure cost control. Third, even the combination of universal coverage and cost control does not guarantee that resource allocation decisions will be made rationally or after careful evaluation."

\section{Survey of Selected Organizations}

Because of the limitations of published literature, a pilot survey was carried out to test the feasibility of collecting information by this method. The goal of the survey was to explore, in selected countries, whether it is possible to establish any relationship 
between HTA results and coverage decisions (the basic decision to allow implementation and payment of any assessed technology). The question of the influence of HTA on the reimbursement process (payment of a specific amount of money for the technology through one of several possible mechanisms of financing health services) was also addressed in the survey.

The survey was organized around these main questions:

- Definition of medical technology;

- Who initiates HTA;

- Types of evaluation conducted;

- Required strength of evidence of effectiveness;

- Laws and regulations concerning medical technologies; and

- Relationship between HTA results and insurance coverage policy.

It was not possible to define a universe to be sampled, so the survey was distributed by subgroup members and others to relevant organizations. Ultimately, 41 usable questionnaires were returned from eight countries (Belgium, France, Germany, the Netherlands, Spain, Sweden, Switzerland, and the United Kingdom). Most of those responding were either government agencies, sickness funds or insurance companies, or advice bodies to government or to payers ( 25 responses came from public organizations).

Because of the unclear sampling frame and the small number of responses, the results can only be considered to indicate some interesting areas for consideration. Furthermore, the answers seemed to indicate difficulties in understanding concepts such as HTA, efficacy, and cost-effectiveness.

Respondents indicated that formal decisions relating to coverage/reimbursement of new health technology are made very frequently in responding countries/organizations, especially in the public health services $(\mathbf{7 7 \%})$, and less frequently in private health care organizations $(62 \%)$. There is often a formal requirement to include HTA results in coverage/reimbursement decisions, according to the respondents. This applies less often to the private sector.

Respondents stated that it can be documented that HTA results influenced decisions by official bodies regarding:

- Implementation of innovative health technology in public health care: $64 \%$;

- Coverage/reimbursement (public sector): 57\%;

- Implementation of innovative HT in private health care: $35 \%$; and

- Revaluation of already utilized HT (in general): $58 \%$.

The kind of evidence considered (or required) when deciding insurance coverage policy are, in order of preference:

1. Experts' opinions;

2. Retrospective clinical studies;

3. Structured information synthesis on state of knowledge;

4. Prospective studies with a control group;

5. Structured information synthesis on clinical practice;

6. Any foreign official documents or assessment reports; 
7. Randomized control trials (never used by 8 out of 25 respondents); and

8. Formal meta-analysis ( $50 \%$ said that they made use of this method, but the other $50 \%$ had never used it).

The answers indicate, despite the small sample size and other problems, that respondents are more likely to use, for practical decision making, low or medium strength of evidence rather than rigorous prospective studies or meta-analysis. Taking the strength of assessment results into consideration, a combination of evidence obtained from experimental clinical studies for efficacy, economic analysis, and formal information synthesis represents an acceptable basis for decisions concerning a medical technology. This combination of assessment methods was used by nine organizations $(22 \%)$. Half of these organizations reported the application of combined strong assessment methods for implementation of coverage decisions.

\section{Conclusions}

The literature review and the survey only yielded some interesting ideas and indicated some problems with coverage decisions. The idea of moving to a standard, such as effectiveness instead of established, is one such important idea. The literature also reflects the difficulty of linking HTA with coverage, especially in a decentralized system such as the U.S. Medicare Program.

Because of limitations of this background information, the subgroup could not depend on these standard methods. It decided to examine some countries in detail to try to achieve some insight into the reality of coverage decision making.

\section{CHAPTER 3: DESCRIPTION OF HEALTH CARE SYSTEMS, COVERAGE, AND HTA}

\section{Health Care Systems in General}

The health care systems of different European countries are very divergent $(1 ; 11$; 45). In some countries general practitioners have a prominent role as suppliers of primary care and as gatekeepers to the system; in other countries primary care is also given by specialists and secondary care is freely accessible. Hospitals can be public and private. Doctors and other individual providers of health care can be independent or salaried. Health insurance can be voluntary or obligatory; social and private health insurance can be complementary or intended for different socioeconomic groups.

Health insurance may function by a reimbursement system (indemnity insurance), or health care providers may have contracts with insurers and be paid via different systems such as fee for service, diagnosis-related systems, or capitation. Home care may be part of the national health care system or it may be part of a locally organized social security system.

In most countries there are mixed systems with different regulations for primary care, secondary care, mental health care, pharmaceuticals, and so on. These diverse systems have their origins in cultural differences, historical backgrounds, or political conceptions in the pluriform European society.

The objectives of health care policy of the different countries are, however, very comparable, even while the means they use to reach these objectives differ widely. Objectives include: 
- Equity: It is of value that all inhabitants of the country have equal rights to what is often called "essential health care," whatever is understood by this term.

- Accessibility: There should be no geographical, financial, or bureaucratic barriers for anyone in gaining access to health care; individual and social well-being should not be based on income (health protection).

- The quality of care: In terms of the structure, process, and outcomes of health care, the quality of care should be good. Good outcome means good health care results as perceived by autonomous individuals (patients). Quality is also considered in terms of expectations for the national figures for life expectancy, neonatal mortality, etc.. At the same time, quality refers to the satisfaction of the people with the functioning of the health care system.

- Cost containment: National costs of health care should not exceed a certain fraction of the Gross Domestic Product.

- Efficiency: This is a combination of the two foregoing objectives. It applies to efficiency on the national level: macro-efficiency. However, in the field of health care it is the combination of all kinds of individual decisions by health care providers and consumers that makes up the cost-effectiveness of the total system. Many of these decisions are made at the bedside. Here professional freedom and the wishes of the patients come into play. Micro-efficiency means that optimal selection of health services and health technology leads to the combination of optimal outcome, minimal damage or side effects for each patient and his or her social surroundings, and minimal costs.

Most European countries would support the idea that these objectives cannot be accomplished without some "interference" in the health care system by national governments. A health care system that is largely left free, such as that of the United States, may reach acceptable and even excellent quality in selected areas but leads to low accessibility for certain groups and very high costs. The problem of a real free market for health care is that it may lead to lower accessibility for the lower socioeconomic classes, the older population, and the chronically ill, especially when it depends heavily on copayment to decrease over consumption of services. Another problem is that indemnity insurance may lead to risk selection by insurers and moral hazard. Furthermore, consumers frequently judge the necessity and quality of health care, which makes patients dependent on the decisions of professionals.

Government "interference" takes two general forms:

1. Detailed top-down regulation of health care by the central government (command-andcontrol type, also the integrated model). The amount of health insurance premiums, total number of medical providers, the extent of covered health care provisions, and prices and tariffs are all under governmental control. This system was usual in the former communist countries and somewhat in the National Health System before recent reforms. Problems in such a system tend to arise in the form of lack of motivation of the medical personnel, poor quality of care and loss of medical freedom, bureaucracy, and waiting lists.

2. Pro-market or pro-competition regulation, generally with encouragement of choice among consumers, and of autonomy and competition among insurers and/or providers. In a regulated health care market system there are four parties:

a) Consumers/patients;

b) Health care providers (doctors, dentists, pharmacists, hospitals, home nursing, services, etc.);

c) Third-party payers (private insurers, sickness funds, health authorities, etc.); and

d) The central government. 
In such a system there is direct payment of third-party payers to providers. This system is normally combined with contracts spelling out the mutual obligations between payers and providers of health care. Both parties negotiate the details of these obligations, which may concern agreements on quality of care, volume, use of guidelines, etc. This payment system has become rather popular with reformers of health care because it offers means to influence microeconomic efficiency. Payment within this system may be implemented by many different methods: fee for service, prospective capitation, salaries, fixed budgets, diagnosis-related groups, etc.

The idea of pro-market regulation is that competition will lead to lower prices and that it will stimulate good quality of care. But the problems with a free market-like system lead governments to keep a strong say in health care, which leads to a mixture of the two types of regulation. In practice this means that there is a restricted amount of autonomy for insurers (and sickness funds) and for providers of health care who are meant to act as each others' countervailing powers.

In some countries there is not a general voluntary or obligatory insurance system, but health care is publicly financed by taxes or special health care premiums. In such countries pro-market regulation is realized by a split between the provision and purchasing of health care.

In the United Kingdom health care purchasing is done by more or less autonomous district health authorities and partly by general practitioner fundholders (32). In Sweden the same function is executed by the county councils. District health authorities dispose of a centrally assigned budget that is based on the characteristics of the population, and they have a certain freedom to purchase and contract selectively health care provisions such as hospital care. It is probable that it makes a difference whether the third-party payers insurers are to compete among each other, not only on the height of premium, but also on quality, health technology utilization, and the amount of medical services that are covered by insurance. It is also important that the third-party payers are allowed to selectively contract with the providers. If this is not the case, there is no real competition between providers.

There are three principal methods by which provision of the benefits, including health technologies, can be arranged:

1. Patients are reimbursed for their medical bills (reimbursement model);

2. The state owns the hospitals and the individual providers are salaried (integrated model); and

3. There are contracts between providers and third-party payers (contract model).

Most countries have a combination of two or three of these systems. Often, there are different systems for primary care, secondary care, pharmaceuticals, longterm care, and other services. In some countries voluntary and obligatory health insurance are complementary; sometimes the higher income classes are privately insured.

In the context of the relationship between health care technology assessment and payment arrangements, it is important to note that the health care systems of most countries seem to converge in a publicly financed system with payments by contracts with third-party payers. These systems comply mostly with cost-containment measures and decentralization, and they allow clinical autonomy. There remains a certain amount of government regulation of prices, budgets for third-party payers and/or hospitals, restricted volumes of providers, and sometimes limitations of big-ticket technologies. 
In the scope of this study, it is an important conclusion that there seems to be a moderate but general shift in regulatory power from providers and governments to the third-party payers.

\section{Regulation of Coverage}

The following short descriptions of the health care systems of eight European countries make clear that mechanisms of coverage decisions are very different. They may be made systematically by government, by third-party payers, or left open. They can also vary in strength and explicitness between field of health care, such as pharmaceuticals, medical devices, and medical procedures.

Insurance coverage in the strict sense means that health technologies are paid by a health plan: technologies can be admitted or removed from the "list of benefits." But there are other possibilities to withhold or restrict the use of health care technologies. A government can refuse to admit technologies to the "market" of a country, often for safety or cost reasons.

Drugs are not admitted when they are unsafe, ineffective, or - and this is new when they are less cost-effective than drugs with the same therapeutic objective and ef fectiveness. Recent European policy changes apply similar rules to medical devices. Medical procedures, especially complicated technologies such as organ or tissue transplantation, can also be forbidden or restricted by governmental regulation (licensing and "planning") for reasons of quality of care and distributional or economic reasons.

Last, but not least, there are methods to influence the use of technologies by health care providers such as hospitals and/or physicians. These methods include contracts concerning volumes, payment regulations, and budgets. They also include increasing providers' responsibility for cost-effectiveness by delivering information on cost-effectiveness to providers and trying to change their attitudes and utilization patterns (see report of the Subgroup on Dissemination). Such a development is especially important for decision making by physicians at the micro-level because they largely determine the indications for use of the technology. Increasing providers' responsibility is also essential for diminishing the use of technologies that never have been proved to be effective.

Strictly speaking, "admittance to the market" and promotion of cost-effectiveness cannot be called coverage policy, but they aim at the same goals. They also need HTA as an indispensable input.

\section{Health Care Systems of Eight Countries}

The country profiles were developed by members of the subgroup. An important reference in most cases was an OECD publication (45).

\section{France}

In France, $99 \%$ of the population is compulsorily insured; nonprofit insurers (mutuelles) and private insurers provide supplementary insurance. There are considerable copayments by patients ( $30 \%$ for "necessary drugs," $60 \%$ for other drugs). The voluntary health insurers $(80 \%)$ act as third-party payers; they are large administrative bodies with little autonomy. The government has a strong influence through price control, budget control of public hospitals, and by planning of equipment and new construction of all hospitals, but not over volumes and type of interventions. A 1991 law transfers the main responsibility for the health facility planning process to regional representatives of the central government; however, private physicians are 
not included in the provisions of this law. The government is currently introducing a program of cost containment and rational use of health services.

There are independent general practitioners and specialists for ambulatory care. Municipal medical centers and public hospitals have salaried doctors; private hospitals usually have doctors working on a fee-for-service principle. There is no referral (gatekeeper) system.

The basis of the financing system is the reimbursement model. Ambulatory care and private hospitals have a contract model. Public hospitals are paid by the integrated model.

For coverage of pharmaceuticals there is an established pre-market approval procedure. After approval the Commission of Transparency (Commission de la Transparence) makes pricing and coverage decisions, considering cost-effectiveness. There is a positive and a negative drug list.

For medical devices pre-market approval is necessary only for reasons of safety. A license of the central government is necessary for a number of big-ticket technologies, such as hemodialysis, CT scanners, MRI, lithotripsy, radiotherapy, etc. This is mainly for reasons of equal distribution around the country.

For procedures a governmental license is necessary for major care, such as transplants, cardiac surgery, neurosurgery, burn treatment, rehabilitation, and treatment for problems of reproduction. Health insurance medical of ficers are working together with physicians on reference protocols (appropriate institutions) in the context of annual agreements.

Traditionally, explicit coverage decisions have been made in France in the area of pharmaceuticals. With recent changes in public policy, explicit coverage decisions are expected to become an important tool for cost containment and cost-effectiveness.

\section{Germany}

In Germany, the entire population with an income up to a certain limit (5100 DM in 1991) is insured in a mandatory sickness fund. Family members are insured without making any contribution and receive the same benefits. About $90 \%$ of the population are members of 500 sickness funds (Krankenkassen), which operate as non-profit statutory corporations. The remainder of the population is generally covered by private insurance.

Most specialists and all general practitioners are independent health care providers. The hospitals are partly private, partly public, with salaried doctors (though doctors may have private practice, too). There is a firm separation between ambulatory health care and intramural care. An effort is being made to integrate office-based and hospital care because this separation causes inefficiencies. Patients have direct access to specialist and hospital care.

Kassenärtzliche Vereinigungen (societies of clinic doctors) represent the ambulatory physicians. They and the hospitals contract with the sickness funds. Beginning in 1999, such contracts will also apply to the investments of the hospitals. The German health care system is essentially an example of the public contract model.

Since 1996 hospital payment has been based on a system of procedural payments and extra payment for 142 surgical procedures. Contract physicians are paid according to a system of points. The point value depends on the negotiated budget and the number of accomplished procedures and is calculated retrospectively by the Kassenärztliche Vereinigung.

Pharmaceuticals approved in the regulatory process are generally paid for by the sickness funds. However, since 1988 the German government has tried to use the reimbursement and pricing system to control expenditures for pharmaceuticals. 
For the coverage of medical devices there is a positive list of reimbursable devices: the suppliers are supposed to present evidence of function, therapeutic benefits, and quality of devices to the central organization of the sickness funds.

Coverage of new diagnostic or therapeutical procedures is decided after assessment by a special committee for new diagnostic and treatment guidelines. The decision is guided by one or more experts, usually university doctors who specialize in the specific field. The process from application until final approval may take longer than a year. This process is not very systematic or explicit, however.

In general, HTA has played a little part in these coverage decisions. However, during 1996 and 1997, an assessment of osteodensitometry (screening for osteoporosis) has been used by the German government in attempting to limit or deny reimbursement. This has been a very controversial issue in Germany.

\section{Greece}

In Greece, the entire population is compulsorily insured, but there are many complaints about the health care system. An estimated $40 \%$ of health financing is paid out of pocket. The main reason is that the government sets hospital charges and doctors' fees considerably below the real cost. There is a small but growing private health insurance sector. Health insurance is a mixture of the contract and the integrated model. About 40 funds and the government are third-party payers.

For primary care, there are rural health centers and polyclinics in urban regions. The population has free access to outpatient departments of hospitals. Hospital distribution and quality of their services are not very adequate. Providers of health care are public employees (in health centers, polyclinics, and public hospitals). Specialists are partly salaried, partly contracted, partly independent. Hospitals are public $(70 \%$ of the beds) and private.

Government control over health quality and health expenditures is weak. There are proposals for a more explicit purchaser-provider split and there is some growing cost-effectiveness conscience within the medical profession.

For the coverage of pharmaceuticals an admission must be approved by the National Drug Association. Coverage is decided by the social security organization, based on whether the drug is reimbursed in the United States or in three European Union countries. There is a positive list of reimbursable pharmaceuticals.

All other coverage decisions are left to each insurance fund, but there is no clearly defined or explicit procedure for such decisions.

\section{The Netherlands}

All inhabitants are obligatorily insured for long-term medical care and $60 \%$ to $70 \%$ of the population are members of one of approximately 20 sickness funds. Practically all others are privately insured. The health care system is a mix of the reimbursement model and the public contract model.

Most individual health care providers, such as general practitioners, specialists, paramedics, dentists, and pharmacists, are private entrepreneurs. General practitioners are paid by capitation (sickness funds) and by fee for service (private insurance). Specialists are usually paid fee for service. But academic specialists, some other specialists, and young doctors are salaried by the hospitals or by the medical faculties. There is a trend for specialists to become salaried.

Most hospitals are private/nonprofit. Referral to secondary care by a general practitioner is obligatory for sickness fund patients and usual for private patients. Hospitals have a global budget. 
Government plans and controls the construction of hospitals; the same law regulates the planning of a number of high-tech facilities. There is strict regulation of prices and tariffs. Sickness funds and, as far as long-term medical care is concerned, private insurers negotiate with providers about prices, tariffs, and budgets. One regionally dominant sickness fund contracts with the regional hospitals. The insurers make contract agreements with the providers and hospitals; selective contracts are possible but rare.

Recent reforms and proposals are addressed to certain health technologies, especially those of "advanced medical care." Prohibition, temporary prohibition (while an HTA is done), and not very strong regulation by favoring certain specific interventions are all possible. A special fund, the Investigational Medicine Fund, prospectively evaluates technologies, especially new technologies that may become candidates for inclusion in the benefit package. There is also global budgeting to the sickness funds to stimulate competition.

For coverage there is a national pre-market approval of pharmaceuticals based on safety and efficacy. Prices are fixed for drugs and regulated by comparing prices in neighboring countries. There is a positive list of pharmaceuticals and a price reference system: co-payment when a drug is higher priced than other drugs with the same therapeutic goal. Extensive information on cost-effectiveness of specific pharmaceutical products is presented by the Health Insurance Board to all physicians. There are also institutionalized deliberations between physicians and pharmacists on the local level concerning the appropriate use of pharmaceuticals.

There is no systematic pre-market approval for medical devices, but there is specific safety control for electrical devices and x-ray equipment.

In the field of medical procedures, a license (according to pre-established standards) is necessary for a number of technologies (e.g., radiation therapy, treatment of end-stage renal disease, genetic screening, cardiac surgery and invasive cardiology, brain surgery, and most transplants). A small number of procedures is either not covered by the sickness funds or only for restricted indications.

A special study involving mostly physicians advising sickness funds and health insurance companies led to the identification of 126 covered technologies of dubious or uncertain benefit. These are presently being evaluated, and it is probable that some will be excluded from coverage.

Thus, the trend in the Netherlands is to base coverage decisions on HTA.

\section{Spain: The Example of Catalonia}

In 1981, Catalonia became the first autonomous region in Spain responsible for its own health care financing, planning, and management within the Spanish health care system. Currently, there are seven autonomous regions responsible for the delivery of health care to the population (Andalusia, the Basque country, the Canary Islands, Catalonia, Galicia, Navarra, and Valencia). In the other 10 autonomous regions the financing, provision, and management of health care is carried out by the National Institute of Health (INSALUD). In Catalonia, the entire population is covered by publicly funded health insurance.

The health care system is a mixture of the integrated model, a contract model, and some reimbursement. Public and private (mainly nonprofit) hospitals are used for the provision of hospital care. This is called the hospital network of public utilization.

Primary care is mainly based on health centers (public and a few private). Basic primary health centers consist of salaried general practitioners; pediatricians, dentists, and nurses are independent. Referral by the general practitioner is necessary 
for access to secondary care; referral is not required for certain emergency cases and diagnostic tests. Doctors in public hospitals and in private nonprofit hospitals are salaried; those working in the private sector are paid fee for service. Public hospitals are budgeted. The recent health care reform in Catalonia promotes the split between financing/purchasing and provision/production of hospitals.

In 1995 a new Royal Decree on Health Services was promulgated. The decree regulates health services provided directly to people by the National Health System and financed by Social Security or state-funded services. HTA issues are included in the decree. The Catalan Health Service is responsible for planning, coverage, financing, and evaluation of health services. The Catalan Ministry of Health plans and controls the construction of hospitals and regulates the planning of high-tech facilities.

The tools for planning and purchasing are the Catalan health plan and contract agreements.

For coverage a pre-market approval procedure (examining efficacy and safety) and price negotiations for pharmaceuticals are carried out on the national level. There is a positive list of covered drugs, with different copayments for short-term or long-term medication.

There is minimal control on medical devices. Some equipment is subject to approval for safety reasons.

The 1995 national Royal Decree on Health Services requires that coverage of new procedures be based on HTA. This decree is now being implemented throughout Spain.

\section{Sweden}

The entire population of Sweden has the right to comprehensive health care with some copayments. The county councils are the main financiers $(60 \%$ state funds and subsidies $28 \%$ ). The councils decide about taxes for health care and about coverage. Sweden's health care system was originally a classic example of a (decentralized) integrated model, but there are now tendencies in the direction of a contract model with a split of providers and third-party payers, health authorities, politicians, and even general practitioner-fundholders.

Primary care is given by district nurses and district physicians (general practitioners or specialists) in health centers; their main task is good public health. Most curative care is given in hospitals. There is no gate-keeping function to secondary care.

In Sweden practically all physicians are salaried. Nearly all hospitals are public and financed by global budgets. Health care regulation is practically completely delegated to the 23 county councils and three municipalities; they constitute together seven regions for the delivery of highly specialized service.

On the national level the Ministry of Health and Social Affairs deals with policy matters and legislation. The role of the central government is restricted to supervision of the taxes by the country councils.

Central registration and pricing of pharmaceuticals as well as quality control and research is made by independent institutions. For coverage the national Pharmaceutical Board must give approval before market introduction, and it negotiates prices of pharmaceuticals. There is a positive list of pharmaceuticals and discussion about copayments.

For medical devices, Sweden only regulates electrical safety. Malfunction must be reported and enables the National Board of Health and Welfare to request technical changes or to stop use. 
County councils decide about admittance and location of big-ticket equipment. There is no formal regulation for procedures. The county councils have a restricted autonomy in regulation of coverage (e.g., periodic breast examination and reproduction treatments differ in different areas of the country).

\section{Switzerland}

Switzerland has a mixed social and private system of health care provision. Each canton (state) has its own health law, and the health care administration is highly decentralized. Since January 1, 1996, a new law has introduced a compulsory basic health insurance with specially regulated cantonal subsidies for basic sickness insurance coverage. Since 1996 the population has the choice between different health plans, including health maintenance organizations (HMOs), which compete with each other, especially on the basis of additional packages of services. An estimated $32 \%$ to $38 \%$ of the population is covered by semi-private or private insurance schemes supplementing the compulsory insurance, but this number is falling.

Hospitals are partially paid by the government. The private medical sector receives no funding from government but is supported by insurance coverage or selfpay. Poor people (taxed income under a certain amount) get financial support from the cantonal government.

The cantonal governments control the planning of their own health care services. Since each canton has its own health care system, there is no reliable information nationally on the utilization of medical services.

The 1996 law provides for a list of approved medical procedures for basic health insurance. Having a list of covered procedures, however, does not mean that all procedures reimbursed by health insurance are listed in detail. This is not the case for the most important procedures, those for which the physicians and hospitals are responsible. There is no approved list (positive list) for these. The principle applied is that all diagnostic and therapeutic procedures carried out by physicians and hospitals are reimbursed unless it has been expressly established that their effectiveness, appropriateness, and cost-effectiveness are not (or not yet) proven. Medical procedures traditionally used in physicians' offices on the basis of the "confidentiality assumption" (assumed to be "appropriate, effective, and economic") are not specified on the positive list.

For other health services there are approved lists (e.g., for drugs, laboratory procedures, preventive procedures).

All requests for the inclusion of new procedures in the positive lists are submitted directly to the federal authorities by interested parties. There is an organized process of assessment and gathering opinions before a coverage decision is made. The process is described in more detail in Chapter 7.

Particularly expensive or complex medical procedures may be subject to a special procedure, in which they are reimbursed by the obligatory health insurance plan only if they are carried out by specially qualified professionals in determined settings. In some cases a registry is required, collecting medical, technical, and economic data. The aim of this conditional coverage is to carry out an HTA and make the revision of coverage after a stated period of time.

Several specific, traditionally applied procedures (e.g., physiotherapy, home nursing, speech therapy) are placed on the medical devices and equipment list in the Decree Concerning Diagnostic or Therapeutic Procedures in Compulsory Health Care Insurance. Evaluation of these areas is planned. 
Thus, HTA is an integral part of the coverage process in Switzerland for those technologies subject to an explicit process.

\section{United Kingdom}

The National Health Service (NHS) offers comprehensive health care to the whole population.

Independent general practitioners have contracts but are paid by capitation; hospitals are practically all public. Specialists in the hospitals are salaried, but they can treat private patients in these hospitals. Ten percent of the population is also privately insured for reasons of status, better quality, and no waiting time.

Originally the NHS was an integrated health care system, but in the last years some radical changes have been made. Since a 1989 government White Paper, market competition has been introduced in the United Kingdom. Hospitals are now selfgoverning. District health authorities and general practitioner-fundholders act as purveyors of health care. These purveyors get budgets based on their population and they negotiate with competing hospitals, which leads to contractual agreements about volumes, costs, waiting times, and other aspects of quality.

For coverage the United Kingdom has pre-market licensing for effectiveness and safety of pharmaceuticals by an autonomous committee. Prices are regulated by the government. There is a selected list of pharmaceuticals and there are copayments.

For medical equipment there is minimal control. There is a special national fund for health care high-cost equipment.

District Health Authorities have limited autonomy to define the content of coverage for medical procedures and technologies.

\section{Synthesis: Input of HTA for Coverage Decisions}

In all countries information on efficacy and safety of pharmaceuticals is necessary before admittance to the market. There is practically no information on the influence of HTA on admittance and/or coverage decisions regarding medical devices and limited information concerning procedures.

A number of countries have moved to formalize input of HTA in coverage decisions. In France and Greece there is no formal input to HTA on coverage decisions, but the situation seems to be changing in France. The relationship between HTA and coverage in Sweden is not entirely clear, although Sweden supports a great deal of HTA.

In the Netherlands a number of HTAs on procedures were carried out under the Investigational Medicine Program; a number of these studies led to planning decisions (admittance to the market) and some of them to coverage decisions. For example, lung transplantation will now be covered in the Netherlands based on an HTA.

In Catalonia (Spain), the regional government has based coverage decisions on HTA reports, especially for high technology. In Spain and in other autonomous regions of Spain, the central and regional governments are making increasing use of HTA reports. Spain is implementing a new plan nationally to include HTA in coverage decisions.

In Switzerland HTA is an integral part of an explicit process of coverage. However, the process does not automatically include all technologies.

In the United Kingdom there are no formal coverage decisions by the NHS, but the District Health Authorities are regularly informed on the cost-effectiveness of medical procedures, which may influence their priorities in purchasing health care. 
The explanations why HTA information is not used more often for decisions on coverage may include the following, based on discussions among Subgroup members after collecting information in their own countries:

- The decision process is too complicated and overcentralized;

- There is insufficient knowledge among the political and economic decision makers of evaluation methods;

- Most decisions are based on informal discussions by politicians;

- There are no incentives and no internal market;

- There is no clear definition of basic health services;

- Effectiveness, costs, and even appropriateness and necessity can often not be proved rapidly enough; and

- A comprehensive evaluation may be prolonged and expensive.

\section{Other Input of HTA in Health Care Policy: Third-Party Payers}

There is a growing importance of contracts and agreements between providers and third-party payers. Developments in the United Kingdom are especially interesting, as the strict split of providers and purveyors has proceeded further there than in other countries (32). Such contracts are meant to specify the volume, the quality, and the costs of health care benefits that are "bought" by district health authorities or fundholding general practitioners. Extensive and up-to-date HTA information is available in the United Kingdom, so these contracts offer good opportunities to improve efficiency in health care. It seems that one of the consequences of the introduction of market principles in health care is not only a power shift from the central government and health care providers (and their organizations) to third-party payers, but also an increased sharing of responsibility of these parties, who become, in a sense, partners in their objective of improving health care and efficiency. Such developments offer opportunities for the input of HTA.

However, another question then must be asked. Who is responsible for the provision of adequate health care? Did physicians lose, or are they losing, their freedom of decision making and of utilizing of health technologies?

\section{Conclusions}

It is difficult to determine how coverage decisions are made, and even more difficult to estimate the impact of HTA results on such decisions. Still, one is left with the impression that HTA results currently have little impact overall. At the same time, such impact is growing.

All countries in Europe are in some sort of a "reform" process, stimulated mainly by concerns about health care expenditures. The process emphasizes changes in reimbursement systems as a method of controlling costs and perhaps improving quality. Those most interested in coverage as a tool believe that it can help in both controlling costs and in assuring more cost-effective care, especially if it is linked to HTA. Furthermore, the growing use of the contract mechanism offers many future opportunities to bring HTA closer to coverage and reimbursement decisions.

The country profiles presented in this chapter show many barriers to the linkage between coverage and HTA. It is quite important to address these barriers if coverage and HTA are to become more closely related to each other. 


\section{CHAPTER 4: THE IMPACT OF TECHNOLOGY ASSESSMENT ON COVERAGE DECISIONS - COCHLEAR IMPLANTS AS AN EXAMPLE}

Cochlear implants were chosen as an interesting and well-documented case study to illustrate the relevance of HTA for coverage decisions in relation to a well-defined procedure. It is obvious that cochlear implants concern only a very small percentage of people and that their economic impact on the different European reimbursement bodies is not very significant compared with other high technologies. Still, the case has some interesting elements that may give ideas for future development in this area.

The main source of information on the case was taken from documents supporting a 1993 Swiss consensus conference on this technology (19). That material was supplemented and updated by those responsible for the case.

\section{The Technology of Cochlear Implants}

Cochlear implantation was developed during the last 30 years and was first introduced to Europe in 1984 . Today cochlear implants $(\mathrm{CI})$ are widely accepted as an appropriate treatment for deafness. More than 10,000 implantations have been performed worldwide. In Europe, nearly all countries are involved in CT. There are currently more than 130 active $\mathrm{CI}$ clinics in Europe.

Nonetheless, there is still considerable controversy with regard to the indications for the procedure: whether to exclude prelingually deaf children and whether to include severely impaired older persons with some hearing remaining in the other ear. Moreover, members of the deaf community and organizations representing them have brought pressure against coverage of this technology, particularly in the case of children. Due to this controversy, decision makers have often felt unsure and have asked for HTA studies as a basis for their coverage decisions.

The result is that $\mathrm{CI}$ is still much discussed and is the subject of a number of clinical and cost-effectiveness studies throughout Europe. Coverage decisions of national health authorities have often been closely linked to the outcomes of such studies.

\section{Coverage of $\mathrm{Cl}$ in Different European Countries}

Full coverage of the CI treatment for all qualifying patients is available in six countries and is provided either by public health insurance schemes, as in the Scandinavian countries, or by the sickness funds that operate in Belgium, Germany, and the Netherlands. In most of the countries, the number of patients is still limited in one way or the other, mostly by limited public or hospital budgets or by restrictions on patient selection criteria.

\section{Major European HTA Studies/Assessments on $\mathbf{C l}$}

In this overview, all known HTA studies were included that have been done in Europe since the beginning of this decade $(2 ; 3 ; 4 ; 5 ; 19 ; 39 ; 50)$. The first HTA study on cochlear implants was published in the Netherlands in 1991 (2). Several studies in different countries followed, and some significant studies are still pending. HTA studies have been done as follows: 1991, the Netherlands; 1993, Switzerland, Catalonia, and Germany; 1994, France and Germany; 1995, UK and Spain; 1996, France and the Netherlands. A European cost-effectiveness study is under way.

The methods of assessment used are shown in Table 3. The studies have had a considerable impact on decision making. The general influence is shown in Table 4. 
Table 3. Methods of Assessment Used in Major European Studies Concerning Cochlear Implants

Methods of assessments:

Prospective primary data collection

Consensus conference, France (children)

United Kingdom

Germany

The Netherlands modelling

Source: Information collected by Thomas Seeger and Richard Cranovsky

\section{Open Questions}

The overview of the available evaluative CI studies indicates that there are major differences from country to country both in policy and practice, with indications for implantation and subsequent rehabilitation and social integration of deaf people. These issues are especially complex with regard to deaf-born infants. The extension of indications or modification of the current policy as far as $\mathrm{CI}$ is concerned remains a controversial issue, confusing decision makers and also dividing the deaf community.

The result of this continuing controversy is that pressures are seen in a number of countries for long-term assessment, for cost/benefit analyses, and for quality-of-life studies. The results obtained (and those from CI registries, e.g., that of Switzerland) should serve as a basis for revision of indications. Moreover, the general development of the CI technology also contributes to the prospective changes in the indications for $\mathrm{CI}$. There might also be modifications in the general concept of the device, in the understanding of electrophysiologic processes, neurochemistry, nerve conduction, physiology of hearing, communicative skills, and behavioral patterns.

The results of HTA refer to a defined window of time in the technology's development. There is a general consensus that a long-term surveillance of this technology and prospective reassessments are necessary. The cost of upgrades, and repairs, as well as the cost of modern (multimedia assisted) methods of rehabilitation/integration, should be taken into consideration in assessment.

\section{Conclusions}

This case study shows that comparable HTA evaluations have been conducted independently and often in parallel in a number of European countries. There are considerable national differences in the requirements as to the scope of the assessment (e.g., medical, economic, societal aspects) and to the strength of evidence of requested $\mathrm{CI}$ evaluative studies.

Table 4. Influence of Studies of Cochlear Implants on Policy Decisions

Influence on general health policy

with regard to $\mathrm{Cl}$ (e.g., indication)

\begin{tabular}{ll}
\hline France & UK \\
Catalonia & Switzerland \\
Spain & France \\
European & The Netherlands \\
Germany/Switzerland & Germany \\
& Catalonia \\
\hline
\end{tabular}

Direct influence on coverage/ reimbursement decisions

Source: Information collected by Thomas Seeger and Richard Cranovsky 
While the CI technology is very complex and still being developed, it is an interesting example where decision makers and those who are responsible for financing health care depend on HTA results as a basis for coverage decisions. The results of these studies either had an influence on general health policy (e.g., extension of medical indications) or, in half of the cases, they directly influenced coverage and/ or reimbursement decisions.

The case also points out the potential value of international cooperation. Considerable resources have been used in supporting and carrying out studies in a number of countries. Convergence of thinking concerning the assessment and use of this technology would be beneficial.

\section{CHAPTER 5: HEALTH TECHNOLOGY ASSESSMENT AND COVERAGE POLICY IN FIVE COUNTRIES - PTCA AS AN EXAMPLE}

Invasive cardiologic therapy (ICT) was chosen as a case study of coverage as a widespread, expensive, and developing technology. It was chosen partly in response to concerns that the cochlear implant case might not be representative of general coverage decisions.

The material for the case study was developed mainly by members of the subgroup, who collected information in their own countries (Catalonia, Greece, the Netherlands, Sweden, and Switzerland). A cross-country case study analysis has been used to check the current state of coverage policies concerning IC technologies and the impact of HTA studies. A mix of qualitative country case study and quantitative (figures from database sources) information has been used.

The full case study deals with the full range of interventional cardiology in considerable detail (13). Because of space limitations, the case of percutaneous transluminal coronary angioplasty (PTCA) is summarized here as the most interesting example in the case study.

\section{Dynamics of the Technology}

The development of PTCA has followed a very distinctive course over time in most western European countries $(48 ; 61)$. At the time of the introduction of PTCA (198083 ), this procedure was regarded as a partial substitute for coronary artery bypass grafting (CABG) (6). Substitution took place most rapidly in university cardiac centers and was clearly seen by 1990 . In nonuniversity cardiac centers, CABG remained the most-used therapy.

In the early 1990s indications for PTCA expanded: multi-vessel PTCA, PTCA combined with thrombolysis in acute myocardial infarction, and PTCA combined with stenting (bailout procedures in failed conventional PTCA) $(33 ; 67)$. This broadening of PTCA indications was again usually pioneered in university cardiac centers. In 1994, in most countries the majority of PTCA procedures (up to $90 \%$ ) were single-vessel procedures. In the more experienced university centers, however, 20 $30 \%$ were multivessel and combined procedures. This expansion of indications caused a 5- to 10-fold increase in PTCA procedures over the last 8 to 9 years, while the number of CABG procedures in that same period doubled in most countries (Tables 5 and 6). Eventually, based on current trends, it is expected that the number of PTCAs will surpass the number of CABG procedures in all European countries. This phenomenon has already been seen in France, Belgium, and Germany (1990), the Netherlands and Spain (1991), and Switzerland (1993), and is about to be seen 
Table 5. Number of CABG Interventions (pmp), 1985-94

\begin{tabular}{lcccccc}
\hline Country & 1985 & 1990 & 1991 & 1992 & 1993 & 1994 \\
\hline Netherlands & 6,789 & 8,640 & 8,703 & 9,173 & 9.205 & 9,870 \\
& $(471)$ & $(583)$ & $(580)$ & $(607)$ & $(605)$ & $(645)$ \\
Sweden & 1,970 & 4,329 & 4,624 & 6,726 & 6,438 & 7,128 \\
& $(246)$ & $(521)$ & $(550)$ & $(800)$ & $(769)$ & $(828)$ \\
Greece & - & 1,907 & 2,509 & 3,072 & 3,916 & 5,744 \\
& & $(185)$ & $(243)$ & $(298)$ & $(380)$ & $(557)$ \\
Spain & 714 & 971 & 1,262 & 1,354 & 1,501 & 1,371 \\
(Catalonia) & $(119)$ & $(162)$ & $(210)$ & $(225)$ & $(250)$ & $(240)$ \\
Switzerland & 1,600 & 2,744 & - & 3,712 & 3,900 & 4,712 \\
& $(253)$ & $(414)$ & & $(550)$ & $(565)$ & $(676)$ \\
\hline
\end{tabular}

Source: Data collected by Michael Bos

in Greece and Catalonia. Other European countries (United Kingdom, Sweden, Italy, and Norway) have not yet reached this point.

\section{Regulation of PTCA}

Some countries have regulations for technologies such as PTCA. In the Netherlands, for example, general legislation (Article 18 of the Hospital Provision Act) to regulate the provision of health care, and in particular high technology care (e.g., PTCA and other invasive cardiology technologies), is used. Similar regulation exists in some regions of Spain, such as in Catalonia under the 1983 Order on Authorization of Health Care Centers. It may be extended to all of Spain under the 1995 Royal Decree on Health Services To Be Covered by the Spanish National Health System.

In Sweden, Switzerland, and Greece there are no national regulations concerning the number or requirements of certain approval before introduction in routine care for invasive cardiology, including PTCA. However, in Sweden, some influence is exerted through recommendations and general regulations (e.g., safety aspects) for medical devices. In Switzerland, the "confidence principle" (see above) was used for PTCA (62).

\section{Effect of PTCA HTA Studies on Coverage Policy Decisions}

HTA studies of PTCA have been carried out and have usually had some effect on planning issues (e.g., estimated need, quality requirements) and payment strategies $(33 ; 42)$.

Table 6. Number of PTCA Interventions (pmp), 1985-94

\begin{tabular}{lcccccc}
\hline Country & 1985 & 1990 & 1991 & 1992 & 1993 & 1994 \\
\hline Netherlands & 2,566 & 7,900 & 8,780 & 9,992 & 10,373 & 12,226 \\
& $(177)$ & $(534)$ & $(585)$ & $(662)$ & $(683)$ & $(799)$ \\
Sweden & 165 & 1,098 & 1,774 & 2,814 & 3,644 & 4,365 \\
& $(20)$ & $(132)$ & $(211)$ & $(335)$ & $(428)$ & $(507)$ \\
Greece & - & 647 & 805 & 954 & 1,601 & 2,332 \\
& & $(62)$ & $(78)$ & $(92)$ & $(155)$ & $(226)$ \\
Spain & 194 & 563 & 723 & 993 & 1,154 & 1,266 \\
(Catalonia) & $(32)$ & $(94)$ & $(120)$ & $(165)$ & $(192)$ & $(211)$ \\
Switzerland & - & 1,862 & 2,774 & 3,138 & 4,519 & 5,590 \\
& & $(281)$ & $(411)$ & $(465)$ & $(655)$ & $(802)$ \\
\hline
\end{tabular}

Source: Data collected by Michael Bos 
In Catalonia, PTCA and CABG studies have been the basis to initiate a geographical preferential reference pattern for these technologies and for the development of specific contracts with providers of this technology.

In the past, the Netherlands has developed planning decrees on cardiac catheterization and cardiac surgery based on an HTA study by the Dutch Health Council (33).

In some cases, the information provided by studies has changed the pattern of payment for the technology. This can be observed in the Netherlands, where the use of laser revascularization has been discontinued since a recommendation to withhold payment on the basis of a cost-effectiveness analysis was published.

Linking payment to appropriate PTCA indications has not been implemented, although there are some hints that this situation may change in the future. For example, Sweden, the Netherlands, and Switzerland have performed appropriateness studies. These studies may be used as a basis to promote the development of clinical guidelines (62). That could be the first step to an appropriateness-based payment policy.

\section{Discussion}

The case of PTCA shows that coverage policy decisions can influence the introduction and diffusion of health technology. While introduction is linked to coverage decisions, diffusion is highly influenced by the financing method. In some countries the financing method and size of the payment are less important than regulatory mechanisms.

PTCA is available in all studied countries. It is paid for mainly through the global budget approach. However, this situation led to the payment for both established clinical indications (on a scientific basis) as well as emerging ones under the same financial umbrella.

Although central and regional/provincial governments have tried to control the implementation of ICT (e.g., PTCA) by planning measures, both through legislation or recommendations, this objective has not been fully met. Some possible explanations for this failure are the improvements in the technology, new indications for PTCA, increase of revascularization procedures due to restenosis, and size of the payment per procedure.

Some countries have a specific coverage-related regulation. However, the case points out some limitations to such an approach: a) the boundaries of "experimental technologies" and the quality of the information required to be accepted as proven are generally not explicit; b) conditions guaranteeing quality of care are not generally addressed; and c) when coverage is established according to a broad category of services, the possibility exists of including a mix of procedures where the safety and short/long-term efficacy and efficiency of some of procedures are unknown, such as in the case of expanded indications of PTCA.

The information provided by HTA studies represents just one factor in a group of interacting forces in the establishment of coverage policy decisions in the countries analyzed. Individual physicians, medical professional bodies, medical advisory boards, and patients also play an important role in coverage policy decisions. The weight of these different forces varies among countries.

Those countries with established HTA programs that have carried out HTA studies of PTCA have generally used them to establish coverage policy decisions. Third-party payers are particularly interested in using information provided by those organizations. Those studies answering a request made by third-party payers have had 
a direct effect in macro-level coverage policy decisions. Studies have also influenced general planning and payment decisions.

The actual effect of those studies on practice or rates of intervention is not known. The context of the health care system influences the use of PTCA at the hospital level and at the bedside. For example, in Sweden HTA studies supported by political institutions resulted in national recommendations to county councils. But those councils have the autonomy to decide whether to follow the recommendations in their process of resource allocation.

Regarding the dynamics of the technology, one may speculate that countries that have decided to reimburse PTCA early on (Belgium, Germany, Switzerland, France, and Netherlands) have also had the most rapid increase. In this context, understanding the specific effects of HTA studies is difficult. Nevertheless, until now solid facts addressed to promote the use and payment based on scientific information about appropriate indications for PTCA have been scarce. The lack of information about new PTCA indications at the time it is needed has helped lead to a situation where third-party payers decide to pay for a health care procedure with unknown short/long-term cost-effectiveness. This situation shows the absence of clearly determined rules of decision making by the organizations financing care.

\section{Conclusions}

There is no uniform system, and no one source of information, for the establishment of PTCA coverage policy decisions in the countries analyzed. The availability of an established organization for health technology assessment is an important prerequisite for those HTA studies to have any impact in coverage policy decisions.

In countries without an established HTA organization, it would be worthwhile to establish effective mechanisms to bring the results of HTA to the attention of coverage policy makers.

Coverage policy decisions alone are not a guarantee for effective and appropriate use. The positive effect at hospital level and at the bedside could be and frequently is accomplished through some complementary activities specific to clinical medicine. Possible tools include clinical guidelines and patient/consumer education based on HTA studies. A dissemination strategy can improve the chance of reaching the desired endpoint (see report of the Subgroup on Dissemination).

In Europe there is no clearly defined model for decision making concerning coverage policy. The tools apparently used in these decisions and their level of application differ among the countries analyzed. International cooperation and communication would be beneficial in sharing information on such technologies as PTCA as well as sharing information on coverage policy.

\section{CHAPTER 6: PHARMACEUTICAL COVERAGE}

Assessment, regulation, and coverage of pharmaceuticals is more explicit and defined in European countries than such processes related to other forms of health technology. Furthermore, coverage decisions are very much influenced by decisions at the level of the European Union. For these reasons, this chapter will separately analyze this area. This chapter is based on a paper written for the project (41).

\section{The Pharmaceutical Marketplace and Its Regulation}

The regulation of pharmaceuticals is the result of the interplay of decisions taken at the level of the European Union (EU) and the decisions of each state. The relationship 
between them is subtle. States are primarily concerned with containing the cost of pharmaceutical consumption as part of publicly financed health care. To a varying extent, states are concerned also with encouraging an industry that has been growing rapidly globally. The central aim of the European Union is to remove obstacles to the free movement of goods while at the same time encouraging research and development to promote exports.

At the EU level, the pharmaceutical industry is viewed as one of Europe's best performing high-technology sectors. Yet this potentially European-wide market remains considerably partitioned along national lines.

The demand for medicines is not controlled by the final consumer but by the doctor who has neither to pay for the product nor to consume it. The financial costs of consumption for the patient are blurred by the insurance system, which bears part or all of the direct costs of medicines. Furthermore, the consumer's ability to transform information into knowledge is limited. The doctor makes the decision about the appropriate therapy. This situation, in the absence of strict legal liability of professionals in most countries, might also lead to inadequate concern by the doctor for the safety and efficacy of medicines prescribed.

The nature of the industry's products is perceived to be a matter of life and death. Medicines are seen as essential in ways that most goods are not. Some fear that as a result, pharmaceutical firms can set whatever price they like (37).

There is no certainty whether the long-term effects of new medicines will be beneficial or harmful (64). In general, no medicine is safe; it may only be safe for a particular purpose. This degree of uncertainty can be reduced by various kinds of clinical trials. However, the trade-offs between the beneficial or harmful effects in this information-generating process are themselves subject to uncertainty. At present there is a considerable amount of drug information, but little scientific evaluation of alternative therapies.

Continued product innovation characterizes the industry, and all major companies are heavily involved in research, competing on the basis of product suitability and differentiation rather than price. The ability to develop novel medicines is the driving force of growth in the industry. The institution of the patent system is of prime significance here, providing legal protection to innovators for 17 to 20 years in most countries. Its effective life is less though, because of the time lag between registering a patent and bringing a product to the market (1).

The role of marketing in creating and maintaining the position of a company is considerable. The medical profession itself depends to a significant degree on pharmaceutical companies for information concerning marketed products.

\section{Consolidating the European Internal Market}

The European Commission has made great efforts to push the European Union towards a single market in medicines. It has tried to create a multistate procedure for marketing approval for medicines. It has achieved agreement on directives on advertising, good manufacturing practice, and on provisions relating to labeling, package inserts, and the licensing of wholesalers.

Nevertheless, existing divergent national policies, combined with the inherent peculiarities of the pharmaceutical market and the structure of the industry, make the completion of a single European market a particularly difficult task. For a single market to become a reality, it would be necessary to remove the further barriers to trade by standardizing pack sizes, dosages, and the names of products marketed under different names in different countries. This should reduce costs and allow a 
pan-European wholesaler to stock less products. Furthermore, there is also a need to standardize the time it takes for market authorization to be given in different member states.

In terms of this report, developing a single market would require standardizing the systems of regulation of prices/profits. There is also a need to align how much patients have to pay for their medicines and to align what drugs are covered by health insurance. As will be shown later in this chapter, some countries have lists of drugs not covered by the insurance (a negative list) and others have lists indicating what insurance will pay for (a positive list).

Progress toward a single market has been given a new impetus with the adoption by the council of two new regulations establishing the European Medicines Evaluation Agency (EMEA) in London and the Supplementary Protection Certificate (SPC).

\section{Market Authorization and Development of the European Medicines Evaluation Agency}

In 1975 the Commission established a committee of representatives of national authorization authorities, the Committee for Proprietary Medicinal Products (CPMP) (18), and set up a multistage CPMP procedure for approval of medicines (22). The aim of the CPMP was to facilitate a company that had obtained a marketing authorization in one member state to obtain marketing authorization in another member state. A multiple authorization was established with the objective of avoiding duplication of procedures and reducing delays in the authorization procedure. Applicants who had obtained authorization in one member state could apply for an extension of the authorization to the authorities of five or more other member states. In case of an objection from member states, the CPMP would have to make a nonbinding recommendation.

The Commission created the Multistate Procedure. The minimum number of states that could be approached for an extension of the original approval was reduced from five to two. CPMP opinions remained nonbinding. The Multistate Procedure was more successful than the Mutual Recognition Procedure, but progress had been slow. Finally, a European agency for the evaluation of medical products and three registration procedures for pharmaceuticals were established (51):

1. A centralized procedure, reserved for innovative products and leading to a single community-wide authorization valid for all 15 member states;

2. A decentralized procedure, which will apply to the substantial majority of products, based upon the principle of mutual recognition, and covering a variable number of member states; and

3. A national procedure, limited in principle to applications of local interest concerning a single member state.

\section{Definition of Innovation}

In the centralized procedure, the EMEA is going to decide if a product constitutes a significant innovation in order to be evaluated under the provisions stated. Criteria for the evaluation of the therapeutic value of medicines have already been developed in Germany, the Netherlands, the United States, and Japan. Innovative products are those which are new worldwide products resulting from a specific inventive activity (8). This constitutes a very broad definition and could actually cover the majority of new chemical introductions on the market. But a clear definition is expected to 
raise opposition from the pharmaceutical industry, whose representatives usually argue that it will have a rebound effect on reimbursement decisions (7).

There are additional problems concerning the definition of what is an innovative product at the European level. These problems reflect the multiplicity of regulatory mechanisms in Europe. Countries that have established criteria for the evaluation of therapeutic effectiveness and innovativeness of new products have a single regulatory organization, and they do not currently use these criteria for pricing and reimbursement decisions.

A basic problem with the centralized system is that it will not be able to deal with all the applications submitted.

\section{The International Conference on Harmonization}

The International Conference on Harmonization of Technical Requirements for Registration of Pharmaceuticals for Human Use (ICH) is an initiative that brings together experts from the regulatory agencies and research-based pharmaceutical industry in the European Union, the United States, and Japan to agree on ways in which technical requirements for registering new medicines (quality, safety, and efficacy testing) in the three regions can be harmonized. The aim is to remove the need to duplicate studies that result from differences in regulations in order to make the pharmaceutical development process more efficient and reduce delays in introducing new medicines. The ICH terms of reference are the following:

- To provide for a scientific dialogue on the differences in registration requirements;

- To identify areas of mutual acceptance of research and development procedures without compromising safety; and

- To recommend practical ways to achieve greater harmonization of registration requirements.

Within the EU, the workload is shared between the Commission for general policy issues and the EMEA on technical aspects, in collaboration with its Committee for Proprietary Medicinal Products and experts nominated by the EU member states (26).

\section{Coverage and Positive and Negative Lists}

There are no European regulations or directives dealing with health care issues related to coverage for health services provision. The only EU policy document is a 1992 Council recommendation that proposed that member states should established positive and negative lists and organize the role of social protection in preventing illness and in treating and rehabilitating the persons concerned so as to meet the following objectives under conditions determined by each state: to ensure for all persons resident within the territory of the state access to necessary health care as well as to facilities seeking to prevent illness and to maintain and, where necessary, develop a high-quality health care system geared to the evolving needs of the population, and especially those arising from dependence of the elderly, to the development of pathologies and therapies and the need to step up prevention (17).

The Council therefore simply recommends that states provide necessary health care, and the manner of doing so is left up to them. The Council also emphasizes the need for high-quality care and the need for developing therapies to meet the evolving needs of the population, but it is the responsibility of the states to define and develop specific policies. 
In an important case (Case 238/82 Duphar), the European court considered the legality of a negative list, excluding certain expensive products from reimbursement by health insurance institutions. The court held that such schemes may be compatible with EU policy, recognizing that member states have a legitimate interest in controlling the health budget.

\section{Pricing and Reimbursement Policies Toward Pharmaceuticals}

While in some areas the Commission has managed to make considerable progress toward a single market, it has had to accept that member states retain substantial autonomy in the crucial area of pricing, reimbursement, and user charges. In addition, pricing and financing systems in the EU are far from similar. The Commission has attempted several times to introduce harmonizing legislation in this field, but it has failed to convince member states to accept binding measures. The principle of subsidiarity, introduced in the Treaty on the European Union, has imposed further impediments to the creation of a single market in the pharmaceutical sector.

In December 1988 the Council adopted a directive relating to the transparency of measures regulating the pricing of medicinal products for human use and their inclusion in the scope of national health insurance schemes (henceforth known as the Transparency Directive) (21). The Commission acknowledged that the directive was an initial step toward harmonization and that further measures should take place progressively. The directive requires that the national authorities adopt transparent, objective, and verifiable criteria when deciding on price or profit regulations or the setting up of limited and positive lists of drugs. It defines a time limit of 90 days on national authorities to agree or set a price on newly introduced products and requires that they state the reasons if they fix a price different from that sought by the company.

In addition, the directive delimits the timing on processing applications for price increases, defines the steps following the introduction of a price freeze, requires by national authorities a classification of products by therapeutic category, and demands that member states set up criteria for judging the fairness of transfer prices. Finally, the directive provides for the establishment of a Committee on Pharmaceutical Pricing Transparency to oversee the operation of the directive.

In 1992 Commissioner Bangemann initiated discussions with the industry on a wider package linked with the industrial policy for the pharmaceutical sector. The result of that meeting was the establishment of a joint Commission-Industry Task Force (IPTF), which led to the March 1994 publication of the Communication to the Council and the European Parliament on the Outlines of an Industrial Policy for the Pharmaceutical Sector in the European Community (16).

\section{The Actions of Member States}

As mentioned above, a central concern of member states has been to control pharmaceutical expenditure. A variety of measures have been adopted with this aim in view operating on patients, doctors, and the industry. Cost-sharing is intended to influence patients' behavior, while attempts to influence doctors' behavior include positive and negative lists, encouraging generics, monitoring doctors' prescribing, and giving budgets to each doctor. Finally, operated on the industry are company budgets or agreed levels of total revenue for the industry and regulating or influencing prices.

The Role of Positive and Negative Lists. A very limited positive list is in effect $100 \%$ cost-sharing for those products excluded from it. Italy's decision in 1994 
Table 7. Use of Positive and Negative Lists for Pharmaceutical Coverage by European Countries

\begin{tabular}{ll}
\hline Positive & \multicolumn{1}{c}{ Negative } \\
\hline Austria & Germany \\
Belgium & Spain \\
Denmark & Ireland \\
Finland & Luxembourg \\
France & United Kingdom \\
Greece & \\
Italy & \\
Portugal & \\
Netherlands & \\
Switzerland & \\
Sweden & \\
\hline
\end{tabular}

Source: Mossialos (41)

to narrow this list from 4,545 to 771 clearly has this effect. Table 7 shows which countries have positive and negative lists. Some countries with positive lists may also have negative lists, but a positive list is assumed here to also cover the negative list.

Encouraging the Use of Generics. Generics were estimated in 1993 to be $12 \%$ of sales in the United Kingdom, about the same order of magnitude in the Netherlands, and about $16 \%$ in Germany. Only the Netherlands provides incentives for pharmacists to seek these lower prices, as a third of the savings can be retained.

Member states have made attempts to influence the prescribing behavior of doctors. One way of influencing prescribing behavior is to promote the use of generics or to allow generic substitution; the position of the member States is shown in Tables 8 and 9 . In the United Kingdom, the government has been successfully promoting the use of generic drugs as one of the measures to keep the drug bill under control. Much depends on the incentives facing the pharmacist. Clearly, a pharmacist has no incentive to substitute generics when paid on the basis of a percentage of the price, even if this is regressive. This is one reason why generic penetration has been high in both the Netherlands and the United Kingdom, where the pharmacist receives a fixed fee per drug item.

France, Spain, and Italy all have plans to develop the generic market. Italy is likely to change to a flat-rate system of remunerating pharmacists to encourage their use.

Table 8. Rights of Pharmacists to Substitution in the EU Member States (1996)

\begin{tabular}{|c|c|c|c|}
\hline $\begin{array}{l}\text { Limited form of } \\
\text { substitution }\end{array}$ & $\begin{array}{l}\text { With doctor's } \\
\text { agreement }\end{array}$ & $\begin{array}{c}\text { In } \\
\text { emergencies }\end{array}$ & None \\
\hline $\begin{array}{l}\text { Spain } \\
\text { Italy } \\
\text { The Netherlands } \\
\text { Germany }\end{array}$ & $\begin{array}{l}\text { Denmark } \\
\text { United Kingdom } \\
\text { Ireland } \\
\text { Portugal } \\
\text { Belgium } \\
\text { Finland } \\
\text { Switzerland }\end{array}$ & $\begin{array}{l}\text { Denmark } \\
\text { Luxembourg }\end{array}$ & $\begin{array}{l}\text { France } \\
\text { Greece } \\
\text { Austria } \\
\text { Sweden }\end{array}$ \\
\hline
\end{tabular}

Source: Mossialos (41) 
Table 9. The Promotion of the Use of Generics by European Countries

\begin{tabular}{lll}
\hline Strongly & \multicolumn{1}{c}{ Yes } & No \\
\hline Germany & Denmark & Belgium \\
The Netherlands & Ireland & Greece \\
United Kingdom & France & Italy \\
& Luxembourg & Finland \\
& Switzerland & Sweden \\
& & Spain \\
\hline
\end{tabular}

Source: Mossialos (41)

Summary of the Methods of Regulating or Influencing Prices. Every member state of the EU regulates or influences the prices of pharmaceuticals. One typical mechanism is to use average prices of other countries, a mechanism followed by Ireland, Italy, and the Netherlands. The Netherlands, for example, uses the average of prices in Belgium, France, Germany, and the United Kingdom. Other countries regulate prices or negotiate prices. Portugal uses the lowest prices among Spain, France, and Italy. The United Kingdom follows a policy of profit regulation.

Paying for New, Expensive Biopharmaceutical or Pharmaceutical Prod. ucts. The issue of financing new, expensive pharmaceutical products, and especially biotechnology products, has generated significant controversy in a number of countries. Several countries have developed special pricing, reimbursement, and delivery policies. The issue of reimbursement of the new protease inhibitors in France early in 1996 generated a hot debate, which was triggered by the National AIDS Council proposal that the choice of recipient be made by national lottery. The National Advisory Ethics Committee stated that a lottery scheme should be the last resort and held only at the local hospital level when choice could not be made on medical criteria. It is believed that the outcry of AIDS groups led the Prime Minister to openly oppose the lottery idea. A committee of experts is expected to define the eligibility criteria. There are two lessons to be learned from this case: $(l)$ what is acceptable in the United States, where a lottery has been operating for a year, may not be acceptable in Europe; and (2) the role of the AIDS groups is very influential and decisive.

Representatives from the Ministries of Health in Italy, Germany, and France met in December 1995 with the aim of preparing the guidelines for the use of $\beta$-interferon $1 b$. It is not known what was the result of this meeting, but it is the first time that government officials met to discuss policy developments for a specific product. This may set a precedent for the future (the main present indication under consideration is treatment for multiple sclerosis).

Several countries have set specific policies for $\beta$-interferon $1 \mathrm{~b}$ and, in some cases, these have been based on HTA. In Denmark, Italy, the United Kingdom, Spain, and Finland, hospital use of $\beta$-interferon $1 \mathrm{~b}$ is either recommended or restricted. Some countries have centrally established eligibility criteria for the use of the product, and Finland has made this a responsibility of local hospitals. Italy went a step further to produce a special ministerial decree for the use of the product and to name in the decree the doctors responsible for its use in each designated provincial center.

In Denmark, the Ministry of Health decided in December 1995 that $\beta$-interferon would be restricted to hospital dispensing (59). In making this decision, the Ministry considered views of the Sclerosis Society, the Danish Society for Research in Multiple 
Sclerosis, and the opinions of the Danish Neurological Society. In early 1996, a unit of the Ministry of Health produced an assessment report recommending a number of criteria concerning the use of $\beta$-interferon in multiple sclerosis (60). The report emphasized that there is still limited knowledge of the drug's effectiveness and no knowledge at all of its long-term effectiveness. Subsequently, the Ministry launched a reference program for $\beta$-interferon. The program includes the guidelines for eligibility criteria for treatment with $\beta$-interferon, practice guidelines for doctors prescribing the drug, and the establishment of a national clinical database. This linkage of assessment and decisions by the Ministry of Health and the development of a reference program for one drug seem to be unique in Denmark, but it may set a precedent for the future.

\section{Conclusions}

Governments are increasingly concerned by the rising cost of health care and, specifically, the cost of pharmaceuticals. The principal factors underlying increased spending are the aging population and, even more, the important technological developments in health care, many of which are cost-increasing. The main response to rising costs has been an increasing series of ad hoc measures to contain them.

Regulatory measures can operate on consumer demand or on supply. The most common measure acting on consumer demand is cost-sharing. Measures acting on supply include: introducing expenditure ceilings through prospective budgets; adopting less costly alternatives to inpatient care; introducing positive and negative lists; controlling the number of products introduced on the market; and influencing authorizing behavior, limiting the use of technologies and controlling pharmaceutical prices. These measures aim to contain expenditure through simply reducing costly services or providing incentives to adopt more cost-effective treatments, or both.

The EU governments are faced with conflicting policies in the field of pharmaceuticals. They find the costs difficult to curb other than by operating indirectly on prices or by user charges. On the other hand, some governments are keen to increase jobs and exports. Thus, EU governments face important choices. The temptation in the short term is to tightly control pharmaceutical expenditure as part of cost containment policies. If they do this in excess, EU companies cannot be expected to accumulate the profits needed to develop the next generation of successful products simply out of their sales abroad. What is more important, and may lead to significant savings and clear priorities in the future, is a fundamental reassessment of medical knowledge. In view of resource limitations, effectiveness is a crucial principle. With more knowledge of cost and clinical effectiveness, more reliable systems of outcomes measurement and disease management can be developed. Thus, one of the main problems is the lack of information about which services and treatments are effective and which are not. One of the priorities, therefore, is to identify and fill this gap in present knowledge.

Recently, pharmaceuticals have been more subject to explicit coverage decisions than earlier, and in some cases HTA has been linked to such decisions. This may be an interesting precedent for the future.

\section{CHAPTER 7: MODELS FOR COVERAGE POLICY}

Coverage decisions largely remain implicit, untransparent, and political. Improving the quality and cost-effectiveness of care seems to require a large input of HTA. In addition, it requires a coverage policy that is more explicit, rational, and transparent. 
Integrating HTA into coverage decision making requires that those making coverage decisions and those doing HTA are closer together. They must consult regularly, understand each others problems, and work together to improve care.

An idealized model for coverage policy involving HTA might include four steps:

1. Identification of the technology in question. The identification might be done by either party. The coverage body must determine if it is a potential priority for an assessment (see Priority Setting Report). If so, it would ask the HTA body for an assessment.

2. Literature review to determine the availability of information. If sufficient information for an HTA is available, the HTA body would propose an assessment to the coverage body, including a time frame for the assessment. If not, the HTA body would propose supporting a prospective, well-designed study, such as a randomized clinical trial, and perhaps a simultaneous cost-effectiveness analysis to develop new information. If this proposal is accepted, a delay of several years until the final decision can be expected. Naturally, the coverage body may reject the option for an assessment and make the decision on other grounds. It can also, depending on the characteristics of a technology and of the clinical condition to which HTA will be applied, propose temporary conditions with coverage (as in Switzerland and the Netherlands).

3. Synthesis of available information, including that on efficacy, safety, efficiency, and social and ethical aspects, leads to an HTA. Extensive expert input is sought in this synthetic process. The synthesis leads to judgments, conclusions, and (perhaps) recommendations from the HTA body or program to the coverage body. While coverage bodies obviously need clear indications concerning the value of a technology, whether recommendations are appropriate depends on the specific context. Some coverage bodies may prefer not to have recommendations, since they have the effect of bringing pressure for a specific action. Other coverage bodies may ask for recommendations to consider.

4. A coverage proposal is developed by the coverage body. After expert review, including review by the HTA body, the coverage decision is made, published, and promulgated.

Some sort of feedback process is also desirable so that coverage decisions can be modified over time.

As already noted, several countries have worked to develop such a process. For example, the Netherlands has published a scheme for the assessment of pharmaceuticals for coverage.

As described in Chapter 3, Switzerland has developed an explicit coverage process. The process is laid out in an extensive manual available in German, French, and English (63). The manual goes far to meet the goal of spelling out a rational, explicit, transparent process.

Figure 1 shows the Swiss process in general terms. Faced with a demand for coverage of a new technology, an information synthesis (limited HTA) will be done. At the same time, the Insurers Organization and the Physicians Organization will be asked if the method is controversial. The synthesis and the opinions are presented to the Federal Coverage Committee, which makes the decision. Generally speaking, if the technology is not considered controversial by either of the provider organizations, it will be covered. If it is considered controversial by one or both organizations, the technology is classified as controversial, which means that an assessment must be done. The staff will prepare an HTA based on available literature, including HTA reports from other countries, and after discussion with the applicant, will make a recommendation to the Coverage Committee. If the HTA is considered to present sufficient documentation of efficacy and cost-effectiveness, it will be covered and entered into the Official Procedures List. If the information is determined not to 


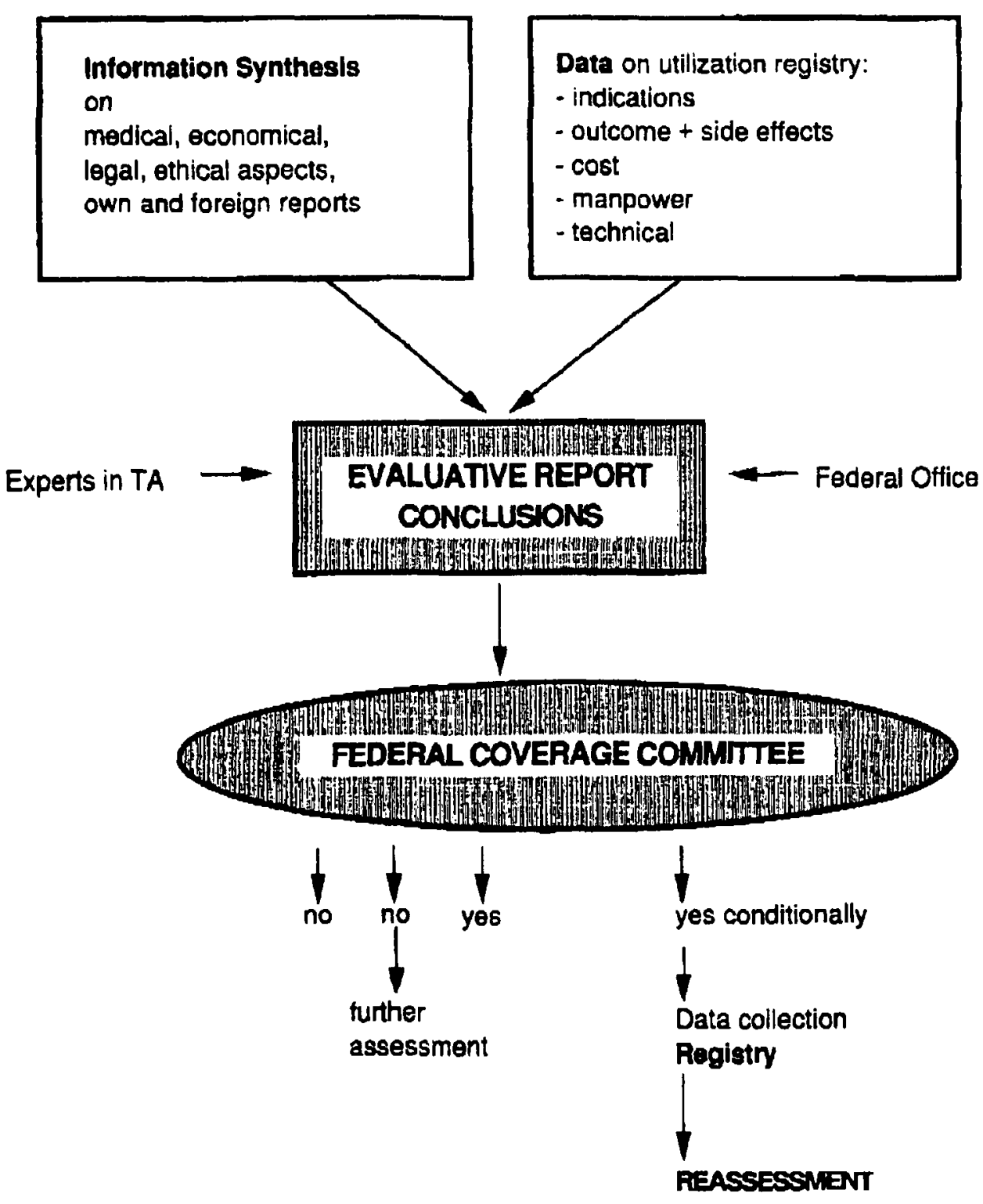

Figure 1. Assessment for coverage decisions.

be sufficient, the Federal Coverage Committee may decide not to cover the technology or may decide not to cover it but to carry out additional assessment. The Committee can also decide to cover the technology. Such coverage may be limited to certain indications. The coverage may also be conditional on a prospective data collection effort or a registry to collect further information on the technology.

The advantage of this system is that it gives the Coverage Committee multiple options in making coverage decisions. It is obvious that the Committee does not just decide "yes" or "no," but can also require a further assessment before making a final decision. In the Swiss case, HTA seems well integrated with the coverage process. 
The advantages of having an explicit and transparent process for making coverage decisions also seem obvious.

\section{REFERENCES}

1. Abel-Smith, B. Value for money in health services: A comparative study. London: Heineman, 1976.

2. Academisch Ziekenhuis Nijmegen. Cochlear Implants. Eindverslag project ontwikkelingsgeneeskunde 1988-1990. Sint Radboudziekenhuis, Nijmegen and Instituut voor Doven, Sint-Michielsbestel. Publikatienummer: IvD/R\&D/9104/01. August 1991.

3. Academish Ziekenhuis Utrecht, Academisch Ziekenhuis Nijmegen, Instituut voor Doven, St. Michielsgestel. Eindsverslag Cochleaire Implantatie bij Volwassenen OG91/010. February 1995.

4. Agence Nationale pour le Développement de l'Evaluation Médicale (ANDEM). L'implant cochleaire chex l'enfant sourd prelingual. Paris, September 1994.

5. Agencia de Evaluación de Tecnologias Sanitarias (AETS). Implantes cocleares. Penel de expertos. Madrid, June 1995.

6. American College of Cardiology/American Heart Association Task Force on Assessment of Diagnostic and Therapeutic Cardiovascular Procedures. Guidelines and indications for coronary bypass surgery. Circulation, 1991, 83, 1125-73.

7. Anonymous. Call for EU definition of "innovation." SCRIP, 1996, 2106, 4.

8. Bangemann Commissioner. Joint answer to written questions no. 2368/92, 2370/92 given by Mr. Bangemann on behalf of the Commission. 26 November 1992.

9. Banta, H. D., Oortwijn, W. J., \& van Beekum, W. T. The organization of health care technology assessment in the Netherlands. The Hague: The Rathanau Institute, 1995.

10. Banta, H. D., \& Saxe, L. Reimbursement for psychotherapy: Linking efficacy research and public policy-making. American Psychologist, 1983, 38, 918-23.

11. Battista, R., Banta, H. D., Jonsson, E., et al. Lessons from the eight countries. Health Policy, 1994, 30, 397-422.

12. Bos, M. Health care technology in the Netherlands. Health Policy, 1994, 30, 207-56.

13. Bos, M., Sampietro-Colom, L., Schilling, J. (eds.). EUR-ASSESS Project Subgroup on Coverage. Technology assessment and coverage policy: The case of invasive cardiology therapy in five European countries. Unpublished background document. Barcelona and Zurich, 1996.

14. Brown, R., \& Luce, B. Technology assessment in decision making by health care providers and payers. Washington, DC: Battelle Medical Technology Assessment and Policy Research Center, 1992.

15. Bunker, J., Fowles, J., \& Schaffarzick, R. Evaluation of medical technologies strategies: Effects of coverage and reimbursement. New England Journal of Medicine, 1982, 306, $620-24$.

16. Commission of the European Communities. Communication to the Council and the European Parliament on the outlines for an industrial policy for the pharmaceutical sector in the European Community. $\operatorname{COM}(93)$ 718, Brussels, March 2, 1994.

17. Council. Recommendation on the convergence of social protection objectives and policies (92-442). Office Journal of the European Communities, 1992, L245/49.

18. Council decision 75/320/EEC of 20 May 1975 setting up a Pharmaceutical Committee. Office Journal of the European Communities, Vol. 147, 9 June 1975.

19. Cranovsky, R., Dillier, N., Seeger, T., Spillmann, T. (eds.) Documentation der KonsensusKonferenz: Cochlear implants. Zurich: Schweizerisches Institut fur das Gesundheitswesen, 1993.

20. Cranovsky, R., \& Racoveanu, N. Magnetic resonance imaging (MRI): Issues in medical technology and health policy. Cracow: Vesalius University Medical Publisher, 1994.

21. Directive 89/105, 1989. Office Journal of the European Communities, 1989, 40, 8.

22. Directive 75/319, 1975. Official Journal of the European Communities, 1975, 147, 75. 
23. Dunning, A., Chairman. Execuive summary: Choices in health care. A report by the government Committee on Choices in Health Care (translated into English). Rijswijk, the Netherlands: Ministry of Welfare, Health and Cultural Affairs, 1992.

24. Eddy, D. Benefit language: Criteria that will improve quality while reducing costs. Journal of the American Medical Association, 1996, 275, 650-57.

25. Eddy, D. What care is 'essential'? What services are 'basic'? Journal of the American Medical Association, 1991, 265, 782-88.

26. Euromedicines evaluation: The striptease begins [editorial]. Lancet, 1996, 347, 483.

27. Fineberg, H. Summing up: Reflections on medical innovation and health care reform. In A. Gelijns, (eds.), Technology and health care in an era of limits. Washington, DC: National Academy Press, 1992, 259-53.

28. Finkelstein, S., Isaacson, K., \& Frishkopf, J. The process of evaluating medical technologies for third-party coverage. Journal of Health Care Technology, 1984, 1, 89-101.

29. Frazier, H., \& Mosteller, F. Medicine worth paying for. Cambridge: Harvard University Press, 1995.

30. Glasser, J., \& Chrzanowski, R. Medical technology assessment: Adequate questions, appropriate methods, valuable answers. Health Policy, 1988, 9, 267-76.

31. Greenberg, B., \& Derzon, R. Determining health insurance coverage of technology: Problems and options. Medical Care, 1981, 19, 967-78.

32. Ham, C. Contestability: A middle path for health care. British Medical Journal, 1996, 312, 70-71.

33. Health Council of the Netherlands, Cardiac Surgery and Interventional Cardiology Committee. Heart surgery and interventional cardiology for adults. The Hague, publication $115 / 01 \mathrm{E}, 1995$.

34. Jonsson, E., \& Banta, D. Health care technology in Sweden. Health Policy, 1994, 30, 257-94.

35. Kirchberger, S. Health care technology in the Federal Republic of Germany. Health Policy, 1994, 30, 163-205.

36. Koch, P. Government reimbursement policy and medical technology assessment. International Journal of Technology Assessment in Health Care, 1987, 3, 607-10.

37. Lindsey, C. Introduction and conclusions. In E. Caglarcan et al, (eds.), The pharmaceutical industry, economics, performance and government regulation. New York: John Wiley and Sons, 1982.

38. Luce, B., \& Brown, R. The use of technology assessment by hospitals, health maintenance organizations, and third-party payers in the United States. International Journal of Technology Assessment in Health Care, 1995, 11, 79-92.

39. Medical Research Council (MRC), Institute of Hearing Research. Cochlear implantation in the UK, 1990-1994. Nottingham, 1995.

40. Ministry of Health and Consumer Affairs of Spain. Real Decreto 63/1955 (English translation prepared by the Canadian Coordinating Office for Health Technology Assessment). Madrid, 1995.

41. Mossialos, E. The regulation of the EU pharmaceutical market. Contract report prepared for the EUR-ASSESS project. London: London School of Economics, December 1996.

42. The Netherlands Society of Cardiology. Guidelines for PTCA (indications and guidelines for interventional cardiology 1992). Netherlands Journal of Cardiology, 1993, 6, 106-15.

43. Office of Technology Assessment. Coverage of laser technology by health insurers. Washington, DC: U.S. Government Printing Office, 1995.

44. Oficina Tecnica d'Avaluacio de Tecnologia Medica (OTAMT). Implants coclears en l'edat periatrica. Barcelona, May 1993.

45. Organisation for Economic Co-Operation and Development (OECD). The reform of health care systems: A review of seventeen OECD countries. Paris: OECD, 1994.

46. Peters, W., \& Rogers, M. Variation in approval by insurance companies of coverage for autologous bone marrow transplantation for breast cancer. New England Journal of Medicine, 1994, 330, 473-77. 
47. Phillips, K., Luft, H., \& Ritchie, J. The association of hospital values of percutaneous transluminal coronary angioplasty with adverse outcomes, length of stay, and charges in California. Medical Care, 1995, 33, 502-14.

48. Pons, J. M. V., et al. Mechnical coronary revascularisation procedures in Catalonia 1980-1993: Trends in patterns of use and implications. Barcelona, Spain: Catalan Office for Health Technology Assessment, 1992.

49. Powe, N., Steiner, C., Anderson, G., \& Das, A. Awareness of providers' use of new medical technology among private health care plans in the United States. International Journal of Technology Assessment in Health Care, 1996, 12, 367-76.

50. Prognos, A. G. Verbesserung der Lebensqualitat durch Cochlear Implants. Projectnummer 551 4182. Basel, October 1993.

51. Regulation 2309/93, 1993. Office Journal of the European Communities, 1993, 214, 1.

52. Reiser, S. Criteria for standard versus experimental therapy. Health Affairs, 1994, 13, 127-36.

53. Ruby, G., Banta, H. D., \& Burns, A. K. Using coverage policy to contain Medicare costs. Journal of Health Politics, Policy and Law, 1985, 10, 141-55.

54. Spiby, J. Health care technology in the United Kingdom. Health Policy, 1994, 30, 295-334.

55. Steinberg, E., Tunis, S., \& Shapiro, D. Insurance coverage for experimental technologies. Health Affairs, 1995, 14, 143-58.

56. Steiner, C., Powe, N., \& Anderson, G. The review process used by U.S. health care plans to evaluate new medical technology for coverage. Journal of General Internal Medicine, 1996, 11, 293-302.

57. Steiner, C., Powe, N., \& Anderson, G. Technology coverage decisions and considerations used by health plans. Unpublished contractor report to the Office of Technology Assessment. Washington, DC, 1995.

58. Stocking, B. (ed.). Expensive health technologies: Regulatory and administrative mechanisms in Europe. Oxford: Oxford University Press, 1988.

59. SundhedsMinisteriet. Sundhedsministerens vesvarelse af spoergsmael $\mathrm{nr}$. 112, stillet den 6. December 1995 fra Folketingets Sundhedsudvalg (Alm. del - bilag 140) apotker; medicin (offentligt). Copenhagen: SundhedsMinisteriet, December 20, 1995.

60. Sundhedsstyrelsen. $\beta$-interferon behandlung af patienter med dissemineret sklerose: Medicinsk tecknologivurdering. Copenhagen: Sundhedsstyrelsen, January 1996.

61. The Swedish Council on Technology Assessment in Health Care (SBU). Percutaneous transluminal angioplasty in coronary revascularisation: Evidence, assessment and policy. Stockholm: SBU, 1992.

62. Swiss 1996 Coronary Revascularization Panel. Swiss guidelines for coronary revascularisation. Zurich, in press.

63. Swiss Federal Office of Social Security. Manual for the standardisation of clinical and economic evaluation of medical technology. Berne: Federal Office of Social Security, 1996.

64. Taylor, D., \& Maynard, A. Medicines, Europe and the NHS. London: King's Fund Institute, 1990.

65. Telling, F. Managed care and pharmaceutical innovation. In A. Gelijns, (ed.), Technology and health care in an era of limits. Washington DC: National Academy Press, 1992, 201-17.

66. Towery, O., \& Perry, S. The scientific basis for coverage decisions by third-party payers. Journal of the American Medical Association, 1981, 245, 59-61.

67. van der Brand, M., and the European Angioplasty Survey Group. Utilisation of coronary angioplasty and cost of angioplasty disposables in 14 Western European countries. European Heart Journal, 1993, 14, 391-97.

68. Weill, C. Health care technology in France. Health Policy, 1994, 30, 123-62.

69. Williams, A. Priority setting in public and private health care: A guide through the ideological jungle. Journal of Health Economics, 1988, 7, 173-83. 